\title{
Frequency Stability Issues and Research Opportunities in Converter Dominated Power System
}

\author{
Ashish Shrestha *(D) and Francisco Gonzalez-Longatt *(D) \\ Department of Electrical Engineering, Information Technology and Cybernetics, \\ University of South-Eastern Norway, N-3918 Porsgrunn, Norway \\ * Correspondence: sthashish2010@gmail.com (A.S.); fglongatt@fglongatt.org (F.G.-L.)
}

check for updates

Citation: Shrestha, A.

Gonzalez-Longatt, F. Frequency

Stability Issues and Research

Opportunities in Converter

Dominated Power System. Energies

2021, 14, 4184. https://doi.org/

$10.3390 /$ en14144184

Academic Editor: Ahmed Abu-Siada

Received: 7 May 2021

Accepted: 8 July 2021

Published: 11 July 2021

Publisher's Note: MDPI stays neutral with regard to jurisdictional claims in published maps and institutional affiliations.

Copyright: (c) 2021 by the authors. Licensee MDPI, Basel, Switzerland. This article is an open access article distributed under the terms and conditions of the Creative Commons Attribution (CC BY) license (https:/ / creativecommons.org/licenses/by/ $4.0 /)$.

\begin{abstract}
Stable power supply has become a crucial thing in the current era of technology and automation. Although the power system has multiple stability issues and causes, frequency fluctuation plays a vital role in normal operation, whereby a system with significant frequency deviation can lead to the needless blackouts of the whole power system. With the rapid growth in power electronic converter (PEC)-based technologies and the huge penetration of nonsynchronous generators, the modern power system is becoming more complex by the day. This paper provides a comprehensive study on the stability issues that occur in modern power systems, mainly due to PEC-based technology integration. The in-depth reasons and the impacts of unstable power systems, along with their controlling techniques, are discussed to generate a clear understanding. Furthermore, the importance of frequency stability in a power system is discussed with respect to some important events that occurred in the past. This paper also discusses some potential techniques that could be performed to overcome the existing and/or upcoming challenges in the upgrading power system.
\end{abstract}

Keywords: low inertia; power electronic converter (PEC)-based technologies; power system stability

\section{Introduction}

Energy generation from renewable energy sources (RESs) leads to numerous benefits for the environmental, financial, technological, social, health, and other sectors. The penetration of RESs can help to reduce the greenhouse emissions generated from thermal power plants and, hence, most countries have developed policies to enhance the implementation of renewable energy by integrating a new form of RESs into the national/international grid system [1]. However, there are numerous challenges in RESs such as high cost, low reliability, poor power quality, and problems in maintenance and monitoring activities [2]. Because of the periodic nature and dependency on weather and environmental factors, the characteristics of the energy generated from RESs such as solar and wind energy are unreliable and unpredictable, resulting in unstable conditions of the main power system [3]. The disturbances created by the unpredictable generation of power from these resources have become an issue in the current power system, and power system developers are in a transition phase to penetrate a significant portion of RESs into the main grid [4,5]. In addition, these resources contain PECs as the fundamental units, which lead to stability issues in the power system. If the system is not modified, having a significant proportion of RESs and PECs means a vulnerable and unsustainable system, which will significantly affect the operation of the power system [6].

Figure 1 presents a classification of the stability issues that occur in electrical power systems. In conventional definitions, there are three types of stability issues: (a) rotor angle instability, (b) frequency instability, and (c) voltage instability. Among these three stability issues, rotor angle stability plays an essential role in system synchronization, which should be resolved within 3 to $10 \mathrm{~s}$ for a transient state and 10-20 s for a steady state, and this is, thus, considered a short-term stability problem [7]. This problem can be adequately solved via the application of power system stabilizers (PSS) or PEC-based exciters, and it can be 
prevented through generator tripping. Similarly, frequency stability indicates the power system's ability to maintain its operating frequency within an acceptable range, whereby instability can occur because of supply/demand unbalance. It takes a few seconds to several minutes for restoration, and this is considered a short-term and/or long-term stability problem. On the other hand, the voltage stability of a power system plays a vital role in maintaining the receiving end voltage within an acceptable range; it takes a few seconds to several minutes for restoration, and this is, thus, considered a short-term and/or long-term stability problem [7]. For short-term voltage stability, automatic voltage regulators (AVR), excitation systems, and induction motors can be used, whereas HVDC interconnections, adjustable tap transformers, and generator excitation current limiters can be used for longterm voltage stability restoration. However, modern power systems contain a considerable number of PEC-based technologies, and they have undergone significant transformation in the last decade; hence, new elements have been introduced in terms of power system stability: (a) converter driven stability and (b) resonance stability [8-11]. Converter-driven stability concerns the oscillation within a power system because of the cross-coupling phenomenon between dynamic electromechanical devices and the transient nature of electromagnetic grid networks [11]. On the other hand, resonance stability takes into account periodic and insufficient energy dissipation within a system, resulting in a form of oscillation [10].

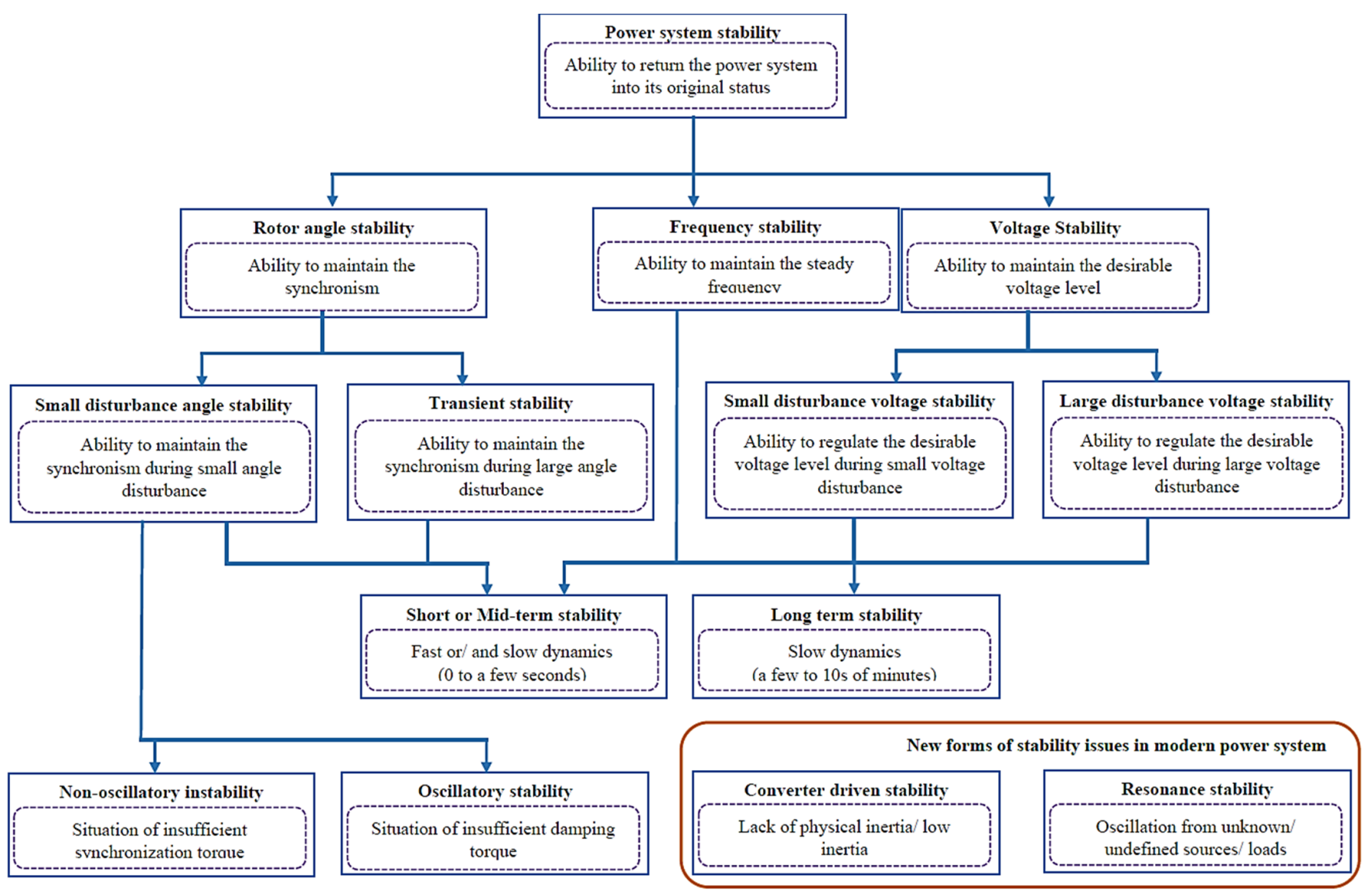

Figure 1. Power system stability classification.

A power system with RES integration can become unstable for two main reasons: (a) the high penetration of PEC-based energy resources such as solar PV and wind turbine reducing the system inertia; (b) RESs being unable to balance the demand/supply chain because of their unpredictable patterns [12-14]. Predicting the time-series value of the demand and generation is very complex and slow; thus, systems can achieve stability by solely focusing on the demand. The high penetration of nonsynchronous generators 
with PECs reduces system inertia and increases the potential of unstable frequency in a power system. Frequency fluctuation plays a vital role in normal operation, whereby a system with comparatively low inertia can lead to needless blackouts of the power system [15]. A drop in system inertia leads to a significant rise in RoCoF and increases the value of nadir frequency. However, most power systems contain protection equipment with conventional operation settings, which need to be upgraded following the massive integration of PEC-based technologies [16]. Several research and development activities have been conducted on voltage stability, rotor angle stability, and frequency control methods. However, limited research activities have considered real-time stability control, despite them being the primary reason behind the numerous blackouts recorded in the last few years [17].

With the introduction of new concepts (i.e., PEC-based technologies) and policies, operation is becoming more complex; hence, some technoeconomic approaches and technologies have to be identified that guarantee the secure and reliable operation of the power system. Several research works have tried to address the issues by proposing various concepts. However, a complex framework in which neglects potential uncertainties may lead to impractical results, with problems arising during the real-world implementation of the proposed method $[18,19]$. Hence, a detailed study on unique and practical methods should be conducted to overcome the existing and/or upcoming challenges in upgrading the power system structure and operation approaches.

The aim of this paper was to present comprehensive information on the stability issues in modern power systems as a result of the high penetration of PEC-based technologies and unpredictable RESs such as solar and wind energy. Furthermore, the objective of this article was to provide a detailed survey on frequency stability issues and their potential solutions via published scientific documents. This paper first introduces the background and a basic overview of the stability problems faced by modern power systems. Section 2 presents an overview of the comprehensive works conducted previously by various researchers and institutions. Section 3 covers the frequency stability concepts in depth, along with their response, regulations, control approaches, and impact on the power system. Some case studies are discussed to analyze the importance of frequency stability in modern power systems. The most important topic of this article (i.e., frequency stability in PEC-based power systems) is discussed in Section 4 . The issues of short-term frequency instability and the challenges caused by PEC-based technologies in power systems are discussed in detail. Furthermore, potential solutions are discussed. Lastly, in Section 5, conclusions are drawn and discussed.

\section{Previous Studies}

Modern power systems are more focused on technoeconomic operation, along with environmental constraints. To improve the operational constraints, the regulatory body can replace the control system with an optimized approach and/or include an optimized supervisory system without modification in the main system [20]. The inclusion of a new control system may become expensive, since the existing system has to be replaced, whereas the second approach is quite popular and practical in rapidly growing systems. However, with the increasing trend of RES integration and PEC-based technologies, existing power systems face new challenges such as unbalanced frequency resilience and low grid inertia [21]; hence, tools need to be introduced that dynamically monitor, analyze, improve, and visualize the system characteristics [22]. It is clear that conventional control technologies are not appropriate for modern power systems; thus, a new way of thinking is necessary [23].

The concept of battery energy storage systems (BESSs) was used to regulate the frequency of a power system in [24,25]. In [26], a self-tuning PID controller was indigested to increase transient stability by using fuzzy logic and thyristor-controlled series compensation (TCSC). Similarly, in [27], a controller was proposed using fuzzy logic and a neural network. Compensators such as static VAR compensators (SVCs) and static compensators 
(STATCOMs) have been used to improve the first swing stability of power systems via a discontinuous control strategy $[28,29]$. A controller was discussed for the improvement of transient stability through the extraction of a synchronous generator in [30]. Teng et al. introduced the concept of EV integration to improve the frequency response of the Great Britain power system [31], while Liu et al. presented the effects on secondary frequency control via EV integration [32]. Integrating EVs as a distributed energy resource (DER) is highly adopted in modern power systems to improve the frequency quality. Similarly, some studies have presented the application of demand-side management (DSM) in power system security [33-35]. Likewise, various techniques have been proposed and investigated to address the stability issues that occur in PEC-based power systems. Figure 2 presents the classification of frequency control techniques.

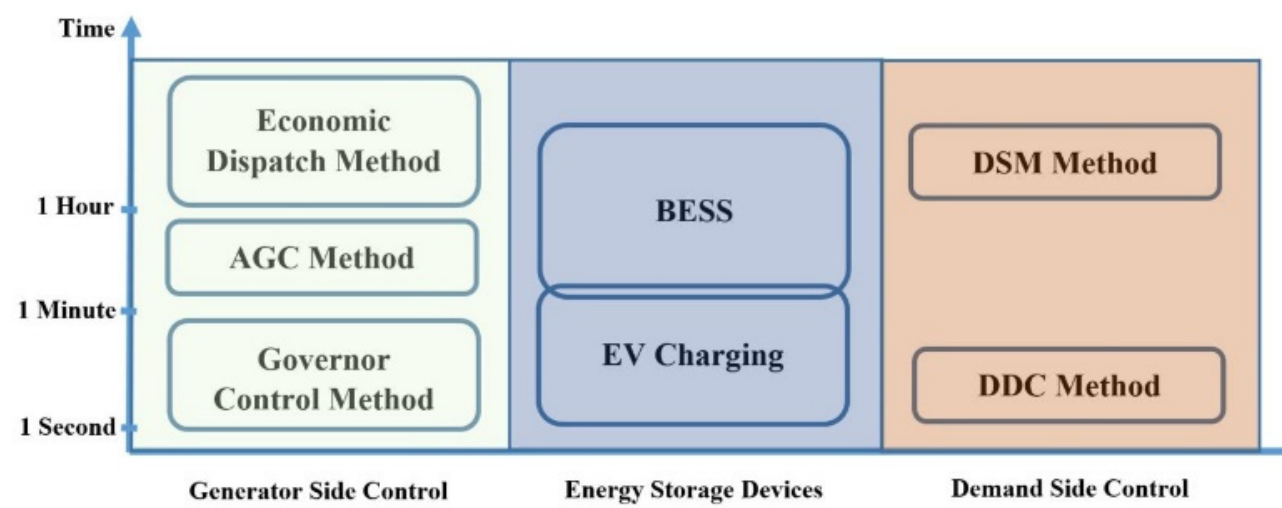

Figure 2. General techniques for regulating frequency in RES-based power systems.

Numerous researches have presented automatic generation control (AGC) as a traditional method to regulate power systems. Usually, the frequency of a system is monitored, whereas the AGC maintains regulation by varying the rate of generation. Behera et al. adopted the harmony search (HS) algorithm as the optimization tool and integral square time square error (ISTSE) as the objective function to identify the best parameters in the controller [36]. AGC was implemented using superconducting magnetic energy storage (SMES) to analyze the performance of both the controller and the power system in [37]. The authors optimized the controller parameters for system stability by using the second law of Lyapunov. In [38], the authors suggested a combined approach using a tilted integral derivative (TID) controller and teaching/learning-based optimization and pattern search (hTLBO-PS) as a new AGC method under a deregulated environment. In [39], an ecological population cooperative control (EPCC) strategy was proposed as an AGC for an islanded smart grid. The authors used the concept of a multiagent system stochastic consensus game (MAS-SCG) to determine the optimal power command for controlling the isolated grid in an optimal cooperative mode. Ramakrishna et al. conducted a detailed transient analysis for individual AGC within a multisource power system [40]. Similarly, an artificial neural network (ANN) was applied to analyze AGC problems in [41]. In [42], the parameter-plane approach was applied to identify the optimal controller parameters, and a sensitivity analysis was carried out to examine stability via AGC. Similarly, in [43], a hybrid technique was proposed for AGC of multiarea power systems by combining the firefly algorithm and pattern search method. As shown in Figure 2, AGC is a general technique that regulates system frequency by controlling the generator-side parameters. Although it works as a secondary response and takes a few minutes, it is considered a fundamental method for the frequency regulation of power systems.

Model predictive control (MPC) is another popular method. Cui et al. proposed a multimodal long short-term memory (M-LSTM) deep learning approach to determine the time-varying variables of composite load modeling (CLM) for a system-wide load study [44]. Similarly, a time-varying model was proposed to identify the parameters for CLM in [45]. A time-varying model was presented to measure the penetration level of 
solar PV in a distribution system in [46]. A method based on MPC was developed to enhance the transient stability of a power system using superconducting magnetic energy storage (SMEA) units [47]. In [48], an approach was presented to determine the real-time system's scheme and regulate the voltage within a limit. Ersdal et al. investigated an MPC-based control method to regulate frequency in a wind-energy-integrated power system by considering three different disturbances: positive, negative, and neutral [49]. A hybrid control system consisting of the MPC method and a neural network was studied to improve the stability of a power system in [50]. A combination of feedback linearization and MPC approaches was used to control the firing angle of a thyristor to improve the transient stability of a system through the regulation of TCSC reactance [51]. Furthermore, the concept of transient energy function (TEF) was combined with MPC to obtain multiple unified power flow controllers (UPFCs), thereby improving system stability [52]. In [20], the authors presented a controlling approach by utilizing the secondary frequency of the power system, whereby a hierarchical-based MPC was used to regulate the primary and secondary frequency. Gomez et al. proposed the concept of a distributed MPC, in which the droop and transferred power were taken as the input parameters to control the frequency and voltage of the microgrid system [53]. Similarly, MPC has been implemented in diverse applications such as to control the TCSC for the enhancement of transient stability [54], to damp out the oscillated power in an HVDC system [55], to manage the distributed generated energy [56], and to stabilize the grid after a contingency [23]. As with other techniques, the important feature of MPC is its plug-and-play structure, facilitating redesign and theoretical evaluation of the structure of a controller. In previous research works, the MPC concept was widely used in the regulation of power systems, especially in terms of frequency stability.

Similarly, various researches presented the dynamic demand control (DDC) approach for regulating the grid frequency. Shrot et al. proposed this concept as a new technique for frequency stabilization in 2007 [57]. Shi et al. presented a comprehensive review of DDC along, with an algorithm and a future vision for system frequency regulation [58]. This study also discussed the various technical and practical factors that play an essential role in the implementation of a DDC approach. Since the individual load is stochastic, and the power system contains a massive number of loads, the adopted approach must identify the predictable pattern for all loads, as well as their generation, and it must provide an appropriate control step to maintain the regulation [58]. On the other hand, Zhu et al. investigated robust load frequency control (RLFC) along with DDC for the regulation of power systems via communication networks [59]. The authors used communication networks in load frequency control (LFC) together with DDC in demand-side response (DSR) to aggregate the well-regulated loads. Qingxin et al. proposed a thermostatic load control (TLC) strategy, a form of DDC, in which thermostatic loads were used, i.e., heating, ventilation, and air-conditioning (HVAC) units and electric water heaters (EWHs) [60]. A hybrid DDC concept was introduced to provide a rapid and steady regulation of primary and secondary frequency in [61], by replacing the generator reserves. A D-partition methodbased LFC approach was proposed for DGs by implementing a PI controller using the conventional Ziegler-Nichols method [62]. A detailed study on the effects of DDC on the frequency was presented in [63], in which it was observed that DDC can minimize the variance (around 30-40\%) of the fluctuation. However, in the DDC method, the randomization of each iteration is necessary to minimize the oscillatory instabilities of the frequency $[57,64]$. As with other conventional techniques, DDC is adopted for its fast response, flexible operation, and economic efficiency.

\section{Frequency Stability in Power Systems}

To operate a power system in a reliable and efficient manner, different parameters must be within an acceptable limit. Among the numerous parameters, stable frequency is one that plays an essential role in the proper operation of a power system. Basically, the frequency of a system should be maintained within an acceptable range, thereby preventing 
issues such as the total generation capacity trying to balance the total load. However, both generation and demand change dynamically, which may lead to an imbalance between the total generation and total demand within that system for an instant of time. This imbalance creates a frequency deviation. If the deviation is within an acceptable range, there will be no significant impact; however, if it crosses a certain threshold, it will affect the power system's operation, reliability, efficiency, and security, as well as degrade load performance, overload transmission lines, and lead to protection failures [7].

Mathematically, frequency fluctuation occurs when the supply/demand balance within a system deviates from the norm (i.e., $P_{M}(t) \neq P_{L}(t)$ ). Here, $P_{M}(t)$ is the mechanical power/generated power, and $P_{L}(t)$ is the electrical load at an instant of time. Basically, the system frequency is directly proportional to the generator's speed; the system's frequency increases with an increase in rotor speed and vice versa. When the system demand increases, the speed of the rotor decreases slowly, and similar results occur in the case of frequency (i.e., $\left.P_{M}(t)<P_{L}(t)\right)$. Similarly, the rotor speed and the frequency increase with a decrease in order of the system load (i.e., $\left.P_{M}(t)>P_{L}(t)\right)$. Hence, the generated power must be equal to the sum of the demand power and power losses; otherwise, frequency deviation will occur. Mathematically, the relationship between frequency and power deviation within a system can be expressed by the swing equation, as given below.

$$
\frac{2 H}{\omega_{s}} \frac{d^{2} \delta}{d t^{2}}=P_{M}-P_{L}
$$

However, in practical cases, the frequency is sensitive to different factors, which are not considered in this study. Nevertheless, the characteristics of the dynamics can be discussed by considering some examples. The authors took two incidents from the Great Britain power system for discussion. Figure 3 shows the dynamic changes in electricity demand and system frequency in the Great Britain power system during the Royal Wedding of Prince William and Catherine on 29 April 2011. Here, significant rises and falls in the electricity demand can be observed, which resulted in drastic frequency fluctuation. Royal Weddings are considered special events in the history of Great Britain, and most British people attended the event whether physically or virtually. Because of the operation of a large number of electronic appliances, the load demand on that day was very high in Great Britain. However, such special events are few in number and should not be missed; hence, as shown in Figure 3, the total electric demand rose significantly during that event, but dropped shortly after its completion. On that day, the British power system observed a demand rise of $2300 \mathrm{MW}$ within a few minutes, followed by a power drop of $3100 \mathrm{MW}$. This type of sharp rise and fall can cause significant fluctuation in the system frequency, hindering its maintenance within the acceptable range. Similarly, Figure 4 presents the frequency fluctuation in the Great Britain power system during the failure of the Sizewell B nuclear power plant on 28 May 2008. As shown in Figure 4, the power system faced three power system failures and one embedded generation failure (i.e., $1993 \mathrm{MW}$ of total failure) in a cascading manner within just $3.5 \mathrm{~min}$. The capacity of the failed power system was higher than the actual reserve capacity of the power system; thus, balance could not be achieved. As such, the frequency crossed the acceptable limit, and the electrical supply (i.e., $546 \mathrm{MW}$ ) of a certain part of the city was cut off for stability maintenance. This accident occurred because of enormous changes on the generation side within a small period. Hence, frequency stability is vital for the proper operation of a power system. 


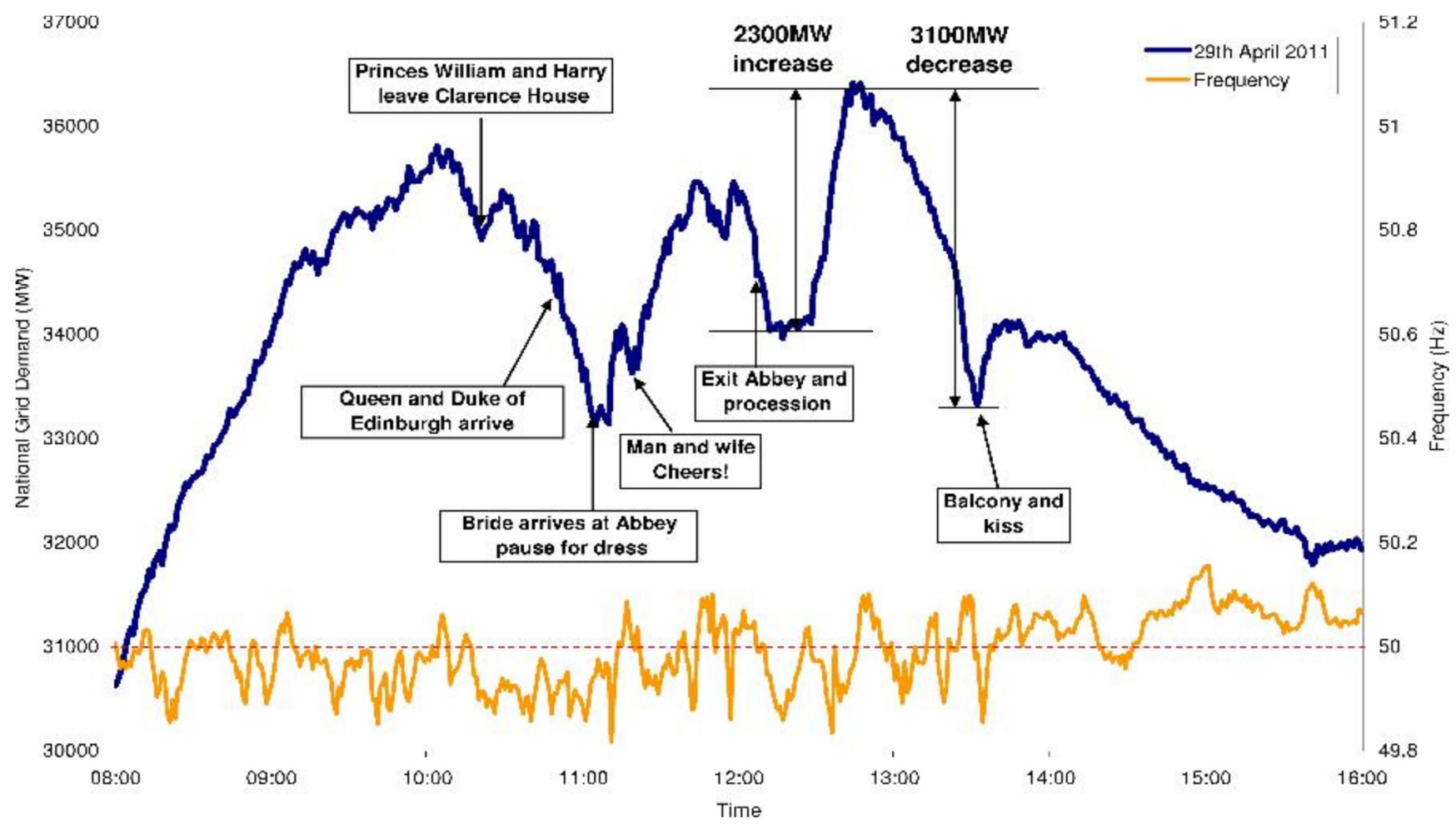

Figure 3. Change in electricity demand and system frequency in the Great Britain power system during the Royal Wedding of Prince William and Catherine on 29 April 2011 [65].

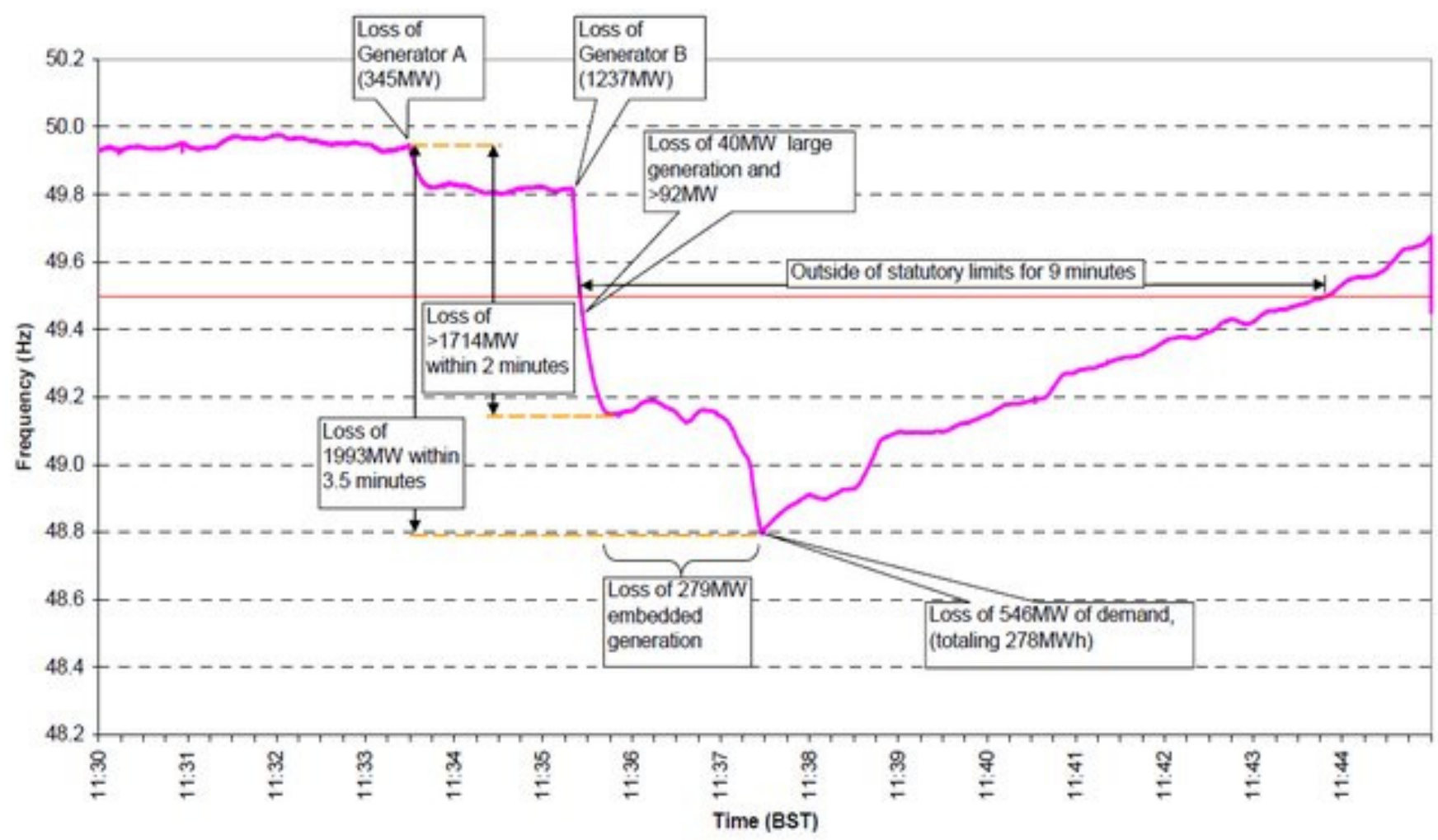

Figure 4. Frequency fluctuation in the Great Britain power system during the failure of the Sizewell B nuclear power plant on 28 May 2008 [65]. 


\subsection{Frequency Response and Regulation Techniques}

To maintain an acceptable frequency range, regular injection and/or withdrawal of generated power takes place. This process must quickly respond to dynamic load changes and establish supply/demand (or energy) balance. The power system is flexible in terms of power generation, which can be maintained during load changes so as to regulate the system frequency [66]. This is a continuous process. As shown in Figure 3, significant rises (2300 MW) and drops (3100 MW) in demand could be observed in the Great Britain power system within a short period (the Royal Wedding). However, the frequency of the system was maintained within the range of $49.8 \mathrm{~Hz}$ to $50.2 \mathrm{~Hz}$; this process is called frequency regulation. In every power system, there is a predefined normal operating frequency band (NOFB) to maintain the system. Table 1 presents an overview of the nominal frequency interval and the critical frequency interval of different countries.

Table 1. Nominal and critical frequency intervals in the power systems of different countries.

\begin{tabular}{cccc}
\hline Country & $\begin{array}{c}\text { Nominal Frequency } \\
\mathbf{( H z )}\end{array}$ & $\begin{array}{c}\text { Critical Frequency } \\
\mathbf{( H z )}\end{array}$ & References \\
\hline Great Britain & $49.5-50.5$ & $47-52$ & {$[67-69]$} \\
\hline Germany & $49.5-50.5$ & $47-52$ & {$[69-71]$} \\
\hline France & $49.5-50.5$ & $47-52$ & {$[69,70]$} \\
\hline Belgium & $49.5-50.5$ & $47-52$ & {$[69]$} \\
\hline Austria & $49.5-50.5$ & $47.5-51.5$ & {$[69]$} \\
\hline Australia & $49.75-50.25$ & $47-52$ & {$[72-74]$} \\
\hline Ireland & $49.8-50.2$ & $47-52$ & {$[69]$} \\
\hline Italy & $49.1-50.1$ & $47.5-51.5$ & {$[69]$} \\
\hline Poland & $49.5-50.5$ & $47-52$ & {$[78-77]$} \\
\hline Denmark & $49.9-50.1$ & $47.5-51$ & \\
\hline China & $49.8-50.2$ & $48-51$ & \\
\hline
\end{tabular}

Because of the differences in electric generation and demand, systems can face power deviation, which further results in frequency instability. For proper and effective operation of a power system, it may balance the demand/supply chain by introducing, for example, a significant reservoir for an extensive system or a BESS for a small system [79]. However, this approach may not be sufficient to maintain the equilibrium state on a real-time basis; thus, the generating plant must have the feature of flexible generation. Flexible generation may support the system in providing instant balance and reducing the potential causes of failure $[79,80]$. In addition, some critical issues may occur following large deviations within a short period, which must be handled for the protection of the whole power system. Hence, control measures are implemented at different levels to maintain the NOFB and to protect the whole power system: (a) primary control, (b) secondary control, (c) tertiary control, and (d) emergency control. Figure 5 shows the frequency control techniques of a conventional power system used to maintain the frequency deviation within an acceptable range in order to operate the system securely and reliably. Similarly, Figure 6 presents the frequency response of a power system under various control actions and their characteristics. As shown in Figure 6, the primary control method is the first action taken by the system for stability, which is fast compared to measures. Similarly, secondary and tertiary control actions are activated more slowly than primary control. The response time for the various control actions is given in the same figure; however, these may vary for different nations and power systems. For a detailed comparison, Table 2 provides a list of control methods and their response periods in various countries. 


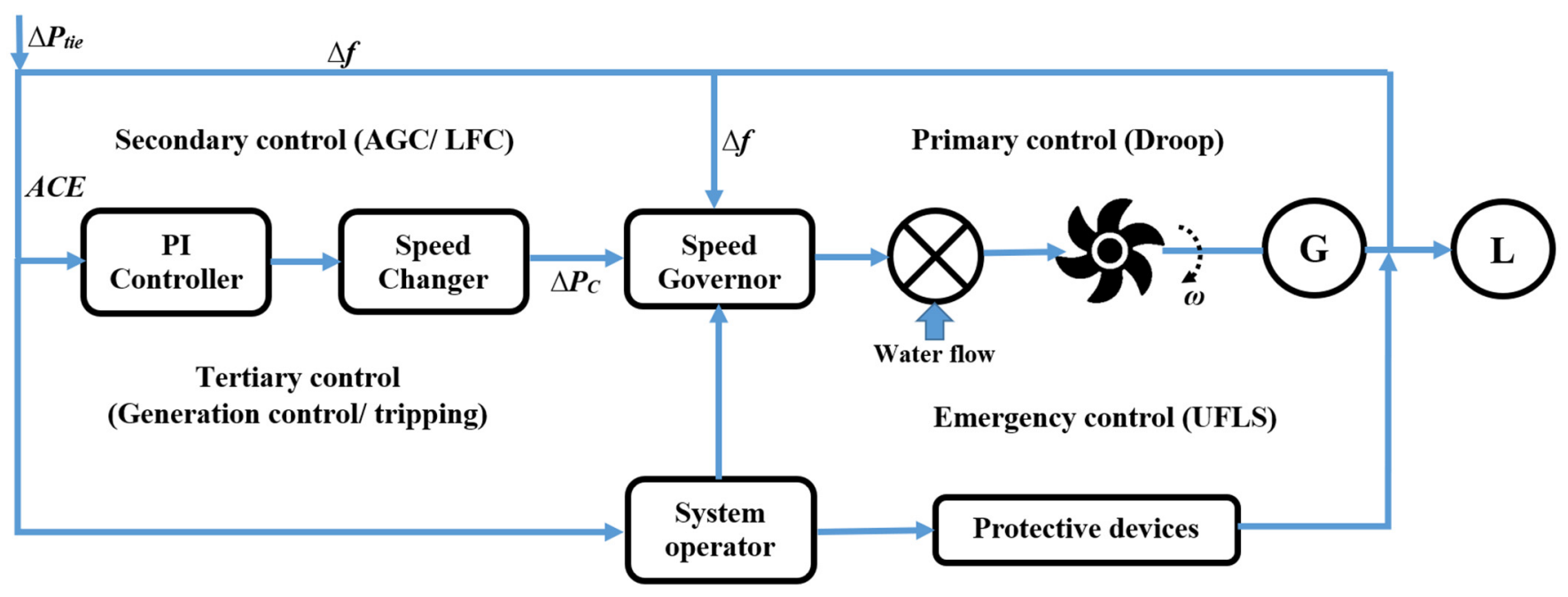

Valve

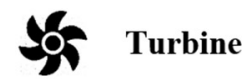

G) Generator

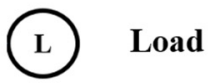

Figure 5. Frequency control techniques/loops in a power system.

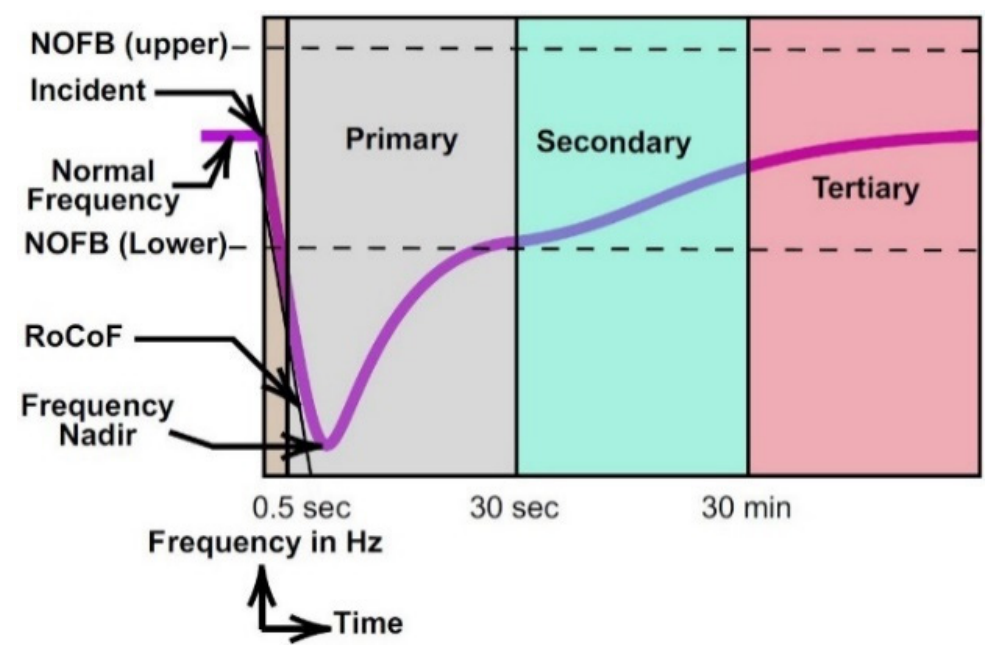

Figure 6. Frequency response of a power system under different control actions.

In a power system, the system frequency is directly related to the angular velocity of the rotor (i.e., $f \infty N_{S}$ ); frequency increases with the increase in rotor speed and vice versa. Hence, frequency control in a conventional power system is akin to the control of rotor speed. At the first stage, the aim is to maintain the speed of the turbine/generator set (i.e., rotor) through the application of a governor mechanism, which senses the rotor speed and regulates the flow of water/steam. A small deviation in speed and frequency can be restored by locally changing the mechanical power outputs. This technique is automatic and based on a drop in the generator, which regulates the frequency disturbance within a few seconds. This is the first stage of the frequency control mechanism and works as the first line of defense in a power system, and it is considered the primary frequency control technique. The primary frequency control technique is very critical for the restoration; therefore, it should meet the standards and specifications for deployment start, full availability, deployment end, droop setting, full deployment, frequency characteristics, and controller insensitivity [81]. 
Table 2. Frequency control responses in different countries.

\begin{tabular}{|c|c|c|c|c|}
\hline Country & Primary Control & Secondary Control & Others & References \\
\hline Great Britain & $\begin{array}{l}\text { Active power of the } \\
\text { generation unit } \\
\text { increases/decreases } \\
\text { within } 10 \text { to } 30 \text { s of the } \\
\text { frequency deviation. }\end{array}$ & $\begin{array}{c}\text { Active power of the } \\
\text { generation unit } \\
\text { increases/decreases } \\
\text { within } 30 \mathrm{~s} \text { to } 30 \text { min of } \\
\text { the frequency } \\
\text { deviation. }\end{array}$ & $\begin{array}{c}\text { High-frequency response is in action, } \\
\text { which acts within } 10 \text { s of the frequency } \\
\text { deviation. }\end{array}$ & {$[67,68]$} \\
\hline
\end{tabular}

The generation unit can achieve $100 \%$ of active power changes within $30 \mathrm{~s}$ and maintain frequency for the next $15 \mathrm{~min}$.
The generation unit is able to achieve $100 \%$ of active power changes within $5 \mathrm{~min}$.
Minutes reserve is adopted, which responds within $15 \mathrm{~min}$. The power supply must be delivered for at least $7.5 \mathrm{~min}$ of the specific quarter hours.

[69-71]

Power plants are capable of setting and enforcing automatic control for the active power and power ramp rate (e.g., an integrated wind power plant contains $1 \mathrm{~min}$ and $10 \mathrm{~min}$ ramp rates).

During the period of severing

Active power of the generation unit generation unit increases/decreases within 3 to $15 \mathrm{~s}$ of the frequency deviation. increases/decreases for a maximum of $1 \mathrm{~min}$.
$50 \%$ of active power increases/decreases within $15 \mathrm{~s}$ and $100 \%$ within $30 \mathrm{~s}$, continued for a maximum of $15 \mathrm{~min}$.
Activated within $30 \mathrm{~s}$ and continued for a maximum of $15 \mathrm{~min}$. deviation, power plants can instantly control their generation as instructed by the TSO.

France/Italy

Denmark

\section{A droop of}

$18,000 \mathrm{MW} / \mathrm{Hz}$ is maintained.
Tertiary control is adopted, which activates along with secondary control, and continues for a maximum $[69,70]$

$$
\text { of } 15 \mathrm{~min} \text {. }
$$

Reserve control is adopted, where the system is regulated within 2 to $3 \mathrm{~min}$ of $0.01 \mathrm{~Hz}$ frequency deviation. If the deviation becomes higher than $0.05 \mathrm{~Hz}, 50 \%$ of system reserve is distributed within $5 \mathrm{~s}$, and $100 \%$ is distributed within $30 \mathrm{~s}$.

A tertiary control mechanism is available as a supportive method of secondary control. Tertiary control is fully activated within $15 \mathrm{~min}$ and continued for a maximum period of $60 \mathrm{~min}$. Moreover, UFLS is implemented with three thresholds (e.g., adopted thresholds in the south of India are $49.5 \mathrm{~Hz}$ and $0.2 \mathrm{~Hz} / \mathrm{s}$, $49.3 \mathrm{~Hz}$ and $0.2 \mathrm{~Hz} / \mathrm{s}$, and $49.3 \mathrm{~Hz}$ and $0.3 \mathrm{~Hz} / \mathrm{s})$.

When the frequency deviation increases and the system enters into non-normal operation, the primary frequency control technique may be unable to restore the system frequency; hence, an additional technique is required for system restoration. The second stage of frequency restoration in a power system is called the secondary frequency control technique. Basically, the primary frequency control technique is used to control the frequency in the short term, whereas the secondary is used to direct the primary one to prevent the system frequency from exceeding the desired limits for a long period [88]. The required power at this stage is delivered by both the spinning and the non-spinning reserve capacities for the balancing of system load and frequency, which is also called the load 
frequency control (LFC) method [89]. The secondary frequency control technique conducts automatic and centralized control by utilizing the system reserve capacity and restores the system frequency within a few minutes [90]. There are two types of control: (a) unit level and (b) system level. In the unit-level secondary control, the reference value of loadfrequency adjustment for the governor is managed by a unit load controller, whereas an automatic generation control (AGC) system is used as the system-level secondary control technique. The unit-level controllers simply supervise the controlling variables that can influence system operation and require primary control actions [90]. On the other hand, the coordination of all power generators within a power system is managed by the AGC, but the AGC is not responsible for direct changes in system frequency; it simply oversees the controllers in initiating primary control actions (as a secondary control method) [91,92]. One of the main objectives of the AGC and/or LFC is to maintain the system frequency by coordinating and exchanging the power (i.e., $\Delta P_{t i e}$ ) with the neighboring control area for a specified period. The area control error (ACE), i.e., a measurement of the actual imbalance of real power in an interconnected power system, is calculated and used to command the controllers with some processed control signals. In the case of stable system frequency, a lower value of ACE (i.e., close to zero) is expected in each power plant area [79]. The deployment time, controller organization, controller cycle time, and controller types should be specified during the secondary control of frequency in a power system [81].

The third stage of the frequency control method is called the tertiary frequency control technique, which is a manual (or automatic) control technique involving a change in the working rate of power generation. It is conducted during situations of serious supply/demand unbalance following sharp frequency deviations, whereby the secondary control is unable to restore the system. It adopts the concepts of adjustment, rescheduling, and deployment of new power generators, and it can take from tens of minutes to hours for the restoration of sufficient secondary control reserve [89]. This technique can be considered the economic dispatch method, and it is implemented in a completely deregulated market setting [93]. Furthermore, tertiary frequency control can be considered a supportive action for secondary control, since it is intended to coordinate the reserves and relieve the secondary control response by lowering the value (near zero) of ACE [94]. Because of disturbances on the generation and/or demand side, if the frequency deviation crosses the acceptable limits and the control techniques fail to restore the system, standby supplies or emergency actions need to be applied to minimize the risk of cascade faults or even system blackouts. A scheme such as under frequency load shedding (UFLS) is used in cases of insufficient generation and/or significant frequency drop. Similarly, generation stations are disconnected in the case of excess generation and/or frequency increases.

\subsection{Case Studies}

Numerous consequences of frequency instability can occur, with the failure and/or system blackout being the major ones. System blackouts happen when some fault occurs in the power system (i.e., power plant and/or transmission medium), and significant power is lost in a part of or the whole power system. A significant drop in power supply on the consumer side (because of the fault) may create power deviation, which may lead to frequency deviation outside of the acceptable range. At first, the control mechanisms discussed in Section 3.1 try to restore the power system; if these are unsuccessful, the system faces cascading failures and even system blackout can occur. In the past, there have been many such cases of blackouts all over the world. Most events occurred because of system failures in terms of generation and transmission lines. The major causes of these failures were either technical issues or natural hazards. Some of the cases are discussed below.

\subsubsection{Power System Blackout in Great Britain on 28 May 2008}

Around 0.5 million people and several industries, businesses, and railways across London, Cheshire, Merseyside, and East Anglia were affected by the power loss on 28 May 2008. It started when the Longannet power station went offline because of some technical issues 
after maintenance. Within $2 \mathrm{~min}$, the Sizewell B nuclear plant also faced issues and failed to produce power. After another minute, embedded generators also faced problems and were removed from the Great Britain power system. Figure 4 provides a clear picture of the events and the frequency fluctuation as a result of these failures. As shown in Figure 4, the power system lost around $1993 \mathrm{MW}$ of power within $3.5 \mathrm{~min}$, which could not be restored by the reserved capacity of the system; thus, the system failed to operate within an acceptable frequency range. As a result, around $546 \mathrm{MW}$ of load was automatically shut down as per the protection precautions $[95,96]$.

\subsubsection{Power System Blackout in Northern and Eastern India on 30 and 31 July 2012}

The Indian power system faced a large failure on 30 and 31 July 2012, which affected around 700 million people from 20 states of the country. As per the inquiry committee, the Central Electricity Regulatory Commission (CERA), the major reasons behind these blackouts were system failures due to some technical and seasonal issues. The day beforehand, the Indian power system faced five issues in the transmission lines: (a) unplanned shutdown of $400 \mathrm{kV}$ Bina-Gwalior-Agra II transmission line, (b) trip of $220 \mathrm{kV}$ Kota-Badod transmission line, (c) phase-to-earth fault in $220 \mathrm{kV}$ Binmal-Sirohi transmission line, (d) trip of $400 \mathrm{kV}$ Bhinmal-Kankroli transmission line, and (e) emergency outage of $400 \mathrm{kV}$ ZerdaKankroli transmission line. The first blackout occurred on 30 July, which affected eight states of the country. Just before this incident, the demand of the Northern Region was calculated to be around 35,669 MW, whereas the generation was only 32,636. At the same time, the system frequency was measured to be $49.68 \mathrm{~Hz}$. The major reasons behind the blackout on 30 July were (a) unplanned shutdown of 400 kV Bina-Gwalior-Agra II transmission line, which created electrical stress on other transmission lines, (b) unscheduled importation of power to the Northern Region from the Eastern Region in large amounts, (c) lack of proper monitoring and coordination by the power utilities, since no action was taken to reduce the total transfer capability after the transmission line failures, (d) stoppage of a few power generation plants, and (e) power swing in the Eastern Region because of the unscheduled import/export and transmission line failure. This blackout affected all sectors and was completely restored after $13.5 \mathrm{~h}$. Then, $21 \mathrm{~h}$ later, three regions (Northern, Eastern, and Northeastern) faced similar issues, whereby consumers (around $48 \mathrm{GW}$ ) were disturbed. However, immediate actions were taken at that instant, and the system was recovered after $8.5 \mathrm{~h}$. During the blackouts, some regions faced issues of overfrequency and high voltages, because of the unscheduled stoppage of power export to other states. Figure 7a,b show the frequency dynamics at different locations of Northern India during the blackouts on 30 and 31 July 2012 [87].

\subsubsection{Series of Blackouts in Venezuela in 2019}

Venezuela faced a long series of power system failures and blackouts in 2019, which affected millions of people, and many people even lost their life. During these blackouts, the transportation, airport, telecommunication, industrial, hospital, education, water services, food products, and household sectors were affected. The major reasons behind these system outages were considered to be irregular system maintenance, mishandling of the system, and lack of technical human resources. The first series of nationwide outages started on 7 March 2019, when a bush fire occurred near the Malena substation in eastern Venezuela, where around $70-80 \%$ of the country's electricity is generated by the Guri dam electricity plant (10,235 MW installed capacity and 47,000 GWh annual generation). The fire affected the $765 \mathrm{kV}$ transmission line between the San Gerónimo B and Malena substations, further resulting in the overload and failure of alternative routes. It took more than 7 days to restore the system and provide electricity. Roughly 1.5 weeks later, the power system failed a second time, which affected 14 states of Venezuela, before recovering after 3 days. A similar problem was recorded after just $24 \mathrm{~h}$ of system restoration. System failures were also observed in April and July in numerous states [97-99]. 

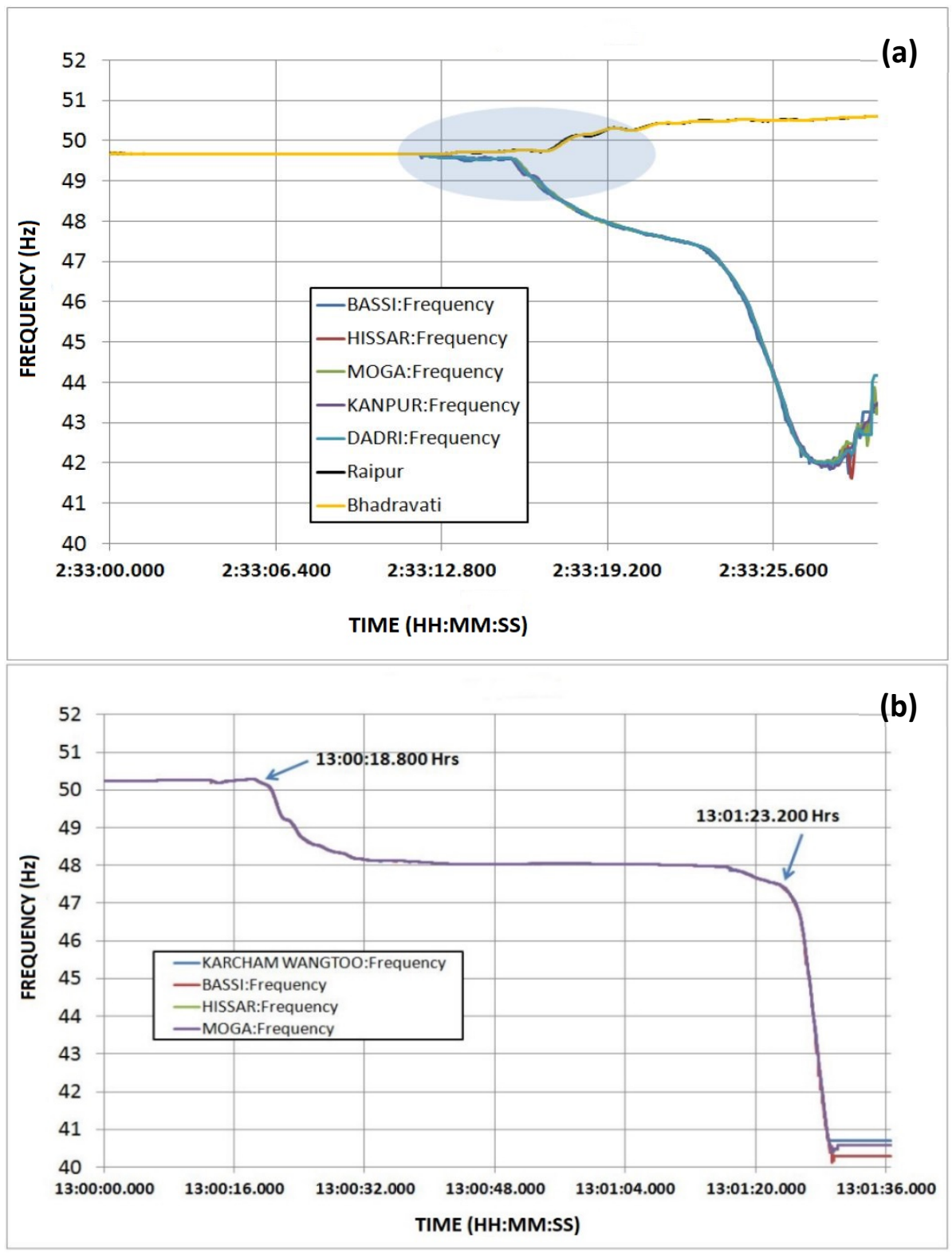

Figure 7. Frequency dynamics at different locations during the blackouts in India (a) on 30 July and (b) on 31 July [87].

\subsubsection{Power System Blackouts in Australia}

Australia faced a power system blackout on 28 September 2016, when a $275 \mathrm{kV}$ singlecircuit transmission line and $275 \mathrm{kV}$ double-circuit transmission line were damaged by tornadoes. Several failures were observed in a cascading manner just after the shutdown of the transmission lines. Six voltage dips were observed in the South Australian power system after the failures. Nine local wind farms reduced their production as per their protection features, which resulted in $456 \mathrm{MW}$ of power reduction within $7 \mathrm{~s}$ (the total demand of the South Australian system was $1826 \mathrm{MW}$ at that instant). There was an attempt to address the reduction in generation by importing power, but this was unsuccessful because of the failure of the Heywood interconnector. Then, the South Australian grid went into isolated mode, and the whole system experienced a blackout in an attempt to maintain the isolated system frequency within acceptable limits. Figure 8 presents the actual dynamics of the South Australian wind farms, along with their generated and reduced power profile, during the system failures. Similarly, Figure 9 shows the frequencies of various sections of the South Australian grid during the system failure. During this 
event, the system frequency dropped to $47 \mathrm{~Hz}$ from $49.5 \mathrm{~Hz}$ in just $0.4 \mathrm{~s}$ with an average RoCoF of $6.25 \mathrm{~Hz} / \mathrm{s}$. The system was restored in around $4.5 \mathrm{~h}$ for $40 \%$ of consumers and around $8 \mathrm{~h}$ for $80-90 \%$ of consumers. Complete restoration was achieved in 12 days via bypassing the transmission lines [73].

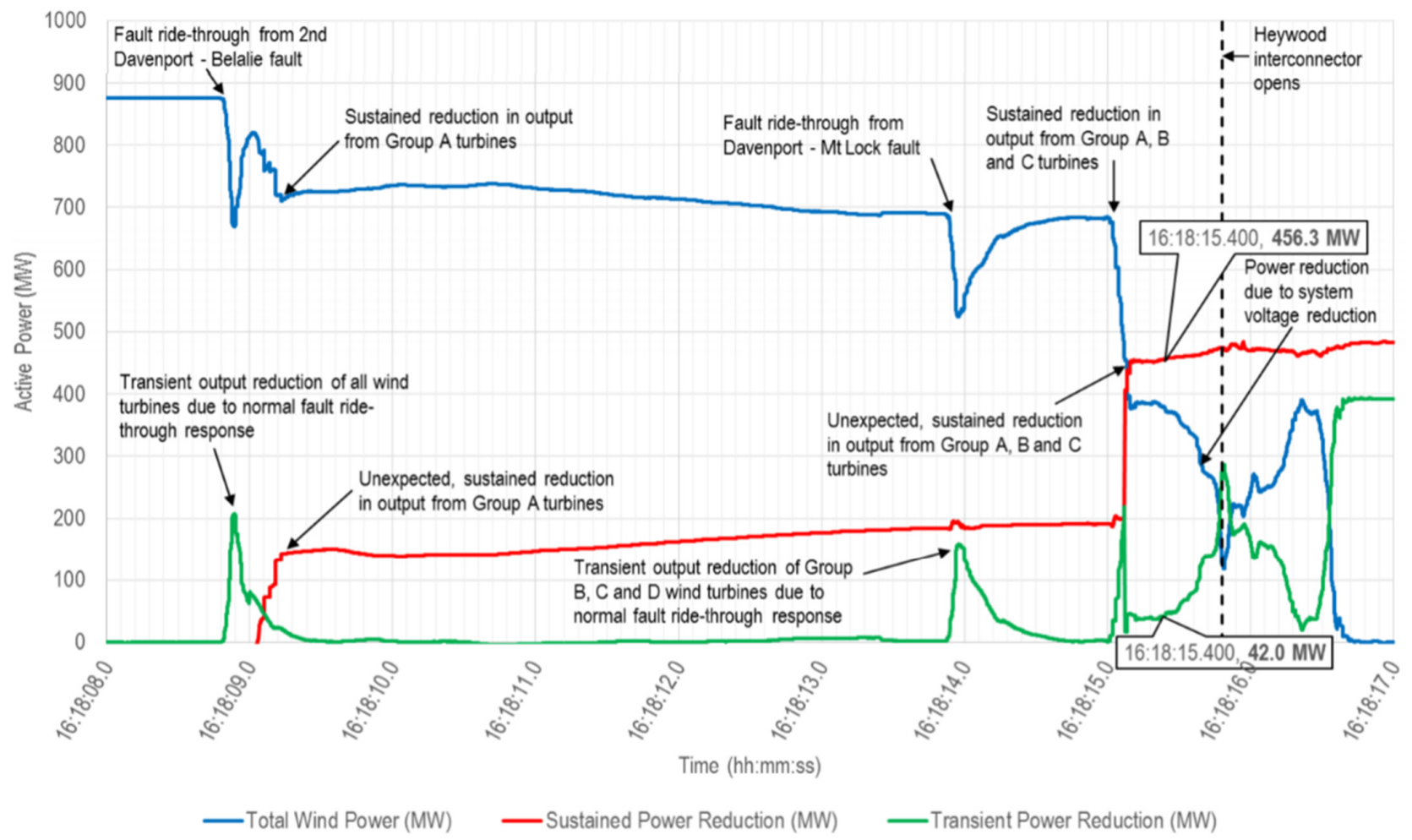

Figure 8. Dynamics of wind farms in South Australian power system during the incident on 28 September 2016 [73].

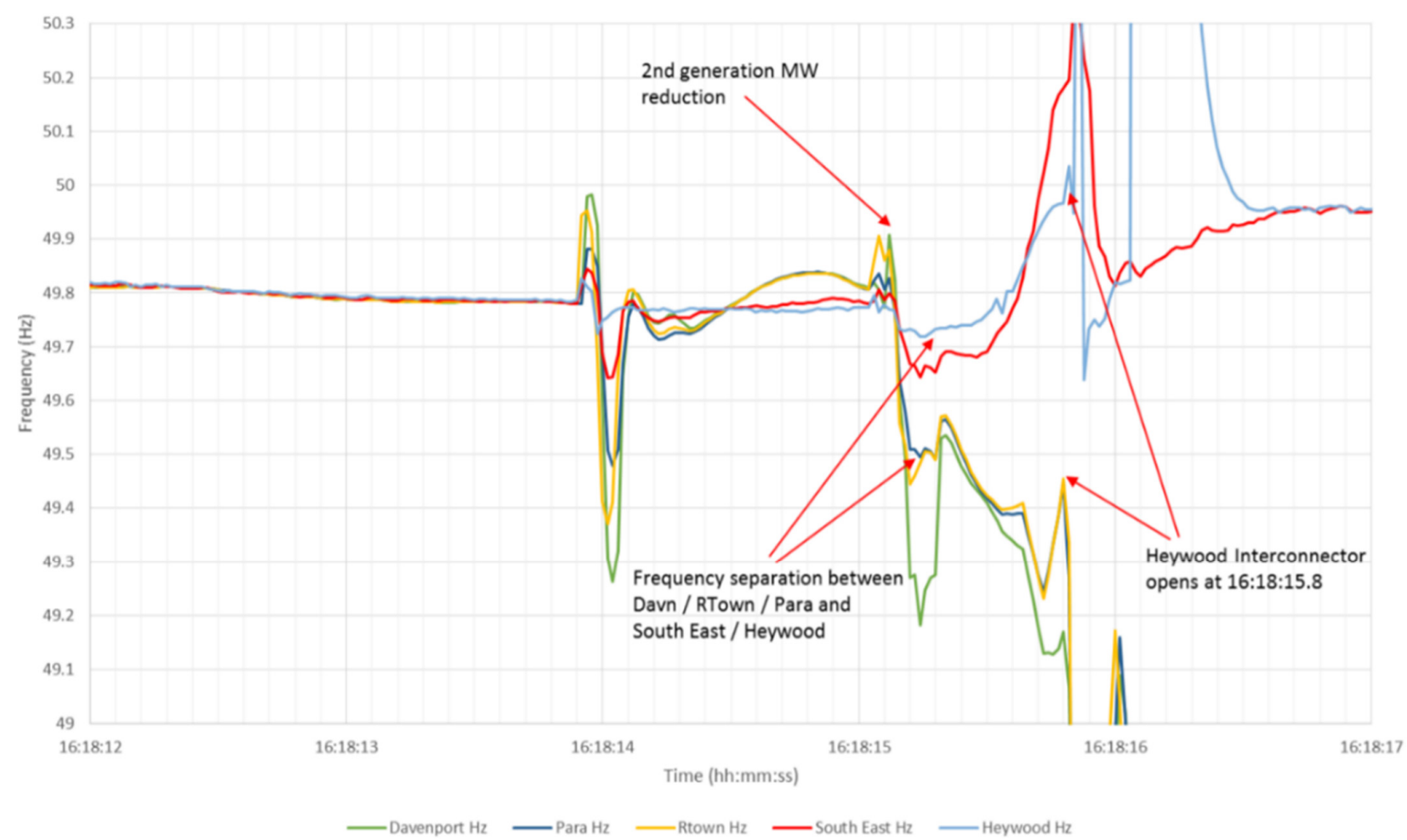

Figure 9. Dynamics of frequency in various nodes of South Australian grid during the failure on 28 September 2016 [73]. 
Furthermore, similar events were also recorded on 1 November 2015 (110,000 households affected), 1 December 2016 (200,000 households affected and restored after $1 \mathrm{~h}$ ), 27 December 2016 (125,000 households affected and restored after 4 days), 20 January 2017 (58,000 households affected), 8 February 2017 (90,000 households affected), and 25 August 2018 in the Australian power system. These events highlighted the vulnerability and sensitivity of the Australian power system. The major issues behind these frequent failures are considered to be the high penetration of PEC-based technologies and the unpredictable nature of RESs, as well as the damage of transmission lines from natural disasters [74].

\subsubsection{Power System Blackouts in California, USA}

California is the state that has faced the greatest number of system failures in the history of the USA. From 2008 to 2017, 4297 power outages were recorded just in California [100]. It is quite challenging to cover all failures; thus, this subsection only discusses the blackout that occurred in California last year. On 14 August 2020, a giant rolling blackout was implemented in California because of the high electrical demand. Because of a huge wildfire, the maximum temperature of California reached up to $130{ }^{\circ} \mathrm{C}$. Because of the COVID-19 pandemic, most people were also staying at their homes and using their electrical appliances. Furthermore, the extreme heatwave forced people to operate their air-conditioning units, which significantly increased the total system demand. According to the data from the California Energy Commission, a large proportion of electricity is generated from RESs, with plans to increase the proportion to $60 \%$ by 2030 . In $2019,21.04 \%$ of electricity in California was generated by solar and wind energy resources [101]. On 14 August, a $470 \mathrm{MW}$ solar power plant and several wind power plants (1000 MW total production) failed because of the excessive demand [102]. At the same time, so-called reliable power generators unexpectedly went offline [103]. The rolling blackout was implemented at around 6:30 p.m., when the power generation from solar power plants was disappearing, and continued until 9:00 p.m. [104]. According to various statements, it seems that this incident occurred because of the supply deficit compared to the high demand.

Several initial causes can lead to system outages. A previous study [105] presented statistical data from a survey conducted from 2011 to 2019 in some parts of the world, showing that around $50 \%$ of system blackouts were initiated due to bad weather and falling of trees, $31.8 \%$ were initiated due to equipment and human failures, $10.6 \%$ were initiated due to some form of vehicle accidents, $1.5 \%$ were initiated due to animal activities, and $6.1 \%$ were initiated due to overdemand of electricity. In 2017, the USA faced a total of 3526 outages with a total duration of 284,086 $\mathrm{min}$ and an average duration of $81 \mathrm{~min}$ [106]. Around 36 million people were affected by these events. In the USA, the power outages were caused by seven significant reasons, with bad weather and falling of trees contributing a significant proportion (i.e., 1159 events). Moreover, 791 outage events were caused by human and equipment errors, 444 were caused by vehicle accidents, 173 were caused by animal activities, seven were caused by overdemand, 244 were planned outages, 15 were caused by theft/vandalism, and 693 events resulted from unknown causes in 2017 [106].

\subsubsection{Inferences}

As we all know, wind energy is quite unpredictable, and solar power plants only produce energy during the daytime; thus, some form of a reliable power plant must be present as a backup. The power system must maintain frequency within an acceptable range; otherwise, the system may fail. When failure occurs, unbalance is created within that power system, which may lead to system blackouts if not resolved properly. The five cases presented above provide a clear map of the importance of frequency stability for the reliable operation of a power system. Among the five case studies, the blackout of Great Britain was caused by power generation failure; 1993 MW of generation was lost within $3.5 \mathrm{~min}$, which could not be recovered by the system in time. The system blackouts in India were the results of transmission line failures. Similarly, in Venezuela, a large proportion of generation was isolated because of transmission line failure. However, in 
the cases of Australia and California, natural disasters were the cause of system failures. In all cases, power systems suffered from instability. Because of the supply/demand unbalance, some parts of or the whole power system faced problems, resulting in forced or rolling blackouts. The British, Indian, and Venezuelan power systems are mainly supplied via conventional power generators (i.e., synchronous generators). However, in Australia and California, a large proportion of electricity is produced through PEC-based RESs. In comparison to conventional power systems, modern power systems with significant PECbased technologies record a high number of system outages. Numerous statements have been made on the penetration of RESs and their issues. With the increase in PEC-based technologies, systems are becoming more complex; therefore, advanced technologies and appropriate approaches must be introduced into the modern power systems.

\section{Open Issues of Frequency Instability and the Way Forward}

Modern power systems are adopting a significant transformation in generation, transmission, distribution, and utilization levels with the introduction of rapidly growing PEC-based technologies, due to the massive integration of PEC-based RESs, including solar $\mathrm{PV}$ and wind turbines, whereas the appliances and control methods in other sectors are dependent on the PECs. As discussed in Section 1, short-term frequency instability can occur in modern power systems because of two main reasons: (a) the high penetration of PEC-based energy resources such as solar PV and wind turbine reducing the system inertia, and (b) RESs being unable to balance the demand/supply chain because of their unpredictable patterns. Modern power systems are becoming more complex because of these rapid transformations. This section presents the issues caused by these transformations in detail, and some of the potential solutions are thoroughly discussed.

\subsection{Issues of PEC-Based Technologies in a Power System}

RESs, especially solar and wind energy, are stochastic in nature. The solar and wind resources have variable trends over multiple timescales (daily and seasonal). On the other hand, demand is also stochastic and varies continuously. In modern power systems, both the generation and the load vary over periods of minutes and hours [107]. Numerous studies have been conducted on the forecasting of solar and wind power generation, which have been further implemented to reduce the uncertainty of power systems [108-115]. However, the forecasted results are not accurate for an exact time scale and may create a drastic deviation in the system frequency, especially in a low-inertia power grid [107]. Thus, the increase in PEC penetration increases the stochastic variation of the active power generation in a power system, which may lead to unpredictable situations within that system [116].

In the conventional power system, synchronous generators work as the source of inertia since the rotating mass provides the physical characteristics within that system. The system frequency is directly associated with the rotation of the machine, and the system inertia created by the synchronous machine helps to maintain the system frequency by minimizing the initial frequency deviations. To do this, the total mechanical inertia has some resistive properties (in virtual mode) with respect to changing the rotation of the machine [117]. As given by Equation (1), a small unbalance in power generation and load can create a frequency deviation within a power system. The frequency response of a power system under an unbalanced condition can be seen in Figure 6. An extended form of Equation (1) is given in Equations (2) and (3). Here, $H$ is the inertia constant, $f$ is the system frequency, $S$ is the rated power of machine, $E_{k i n}$ is the kinetic energy, $H_{s y s}$ is the equivalent inertia of the whole power system, $S_{\text {sys }}$ is the system base, and $H_{i}$ and $S_{i}$ are the inertia and rated power of the $i$-th machine.

$$
H=\frac{\left(J \omega_{0}^{2}\right) / 2}{S}=\frac{E_{k i n}}{S}=\frac{H_{i} S_{i}}{S_{\text {sys }}} .
$$




$$
H_{s y s}=\frac{E_{k i n, s y s}}{S_{s y s}}=\frac{\sum_{i=1}^{n} H_{i} S_{i}}{S_{s y s}} .
$$

From the above equations, it is clear that the system inertia is directly proportional to the kinetic energy of the machine for a constant rated power; with an increase in the proportion of kinetic energy (i.e., synchronous type generation), the system inertia increases. The conventional power system contains synchronous generators as the source of kinetic energy, as well as the system inertia, but modern power systems have both less kinetic energy and less inertia. On the other hand, most appliances and the equipment control mechanisms adopted in modern power systems are based on PEC technologies, which significantly reduces the inertia. The rate of inclusion of such technologies is increasing day by day, resulting in decreases in system inertia at a drastic rate [118].

In a power system with multiple generators, each machine should run at the same frequency (i.e., synchronism). If a big power deviation takes place, individual power generators within a power system may lose synchronization, followed by dissimilar fluctuating motions around the center of inertia (COI) $[119,120]$. At this stage, the frequency of each unit may not be the same, instead presenting an oscillating tendency. The rate of oscillation is dependent on the difference between $P_{M}(t)$ and $P_{L}(t)$, as given in Equation (1). However, the frequency of each unit is closed to the COI (see Equations (4) and (5)), and the damping and inertial forces among the units try to pull the whole system back into synchronization [120]. If these forces are unable to maintain the system in its original state, some form of control mechanism should be activated to maintain system stability. From Equations (5) and (6), it is clear that the system frequency and its changing rate are directly related to the inertia of the power grid. A lower system inertia leads to a higher fluctuation of frequency. For a better visualization of these issues, Figure 10a,b can be analyzed, which present the frequency dynamics for different inertial constants and power deviations. From Figure 10a, it can be seen that the reduced system inertia creates a higher frequency deviation, which may lead to an unstable power system. Similarly, Figure 10b shows the dynamic characteristics of the frequency with changes in the power deviation. Here, for analysis, the values of the constants in the transfer function were taken from [7].

$$
\begin{gathered}
f_{\mathrm{COI}}=\frac{\sum_{i=1}^{n} H_{i} S_{i} f_{i}}{\sum_{i=1}^{n} H_{i} S_{i}} . \\
f_{\mathrm{COI}}(t)=1+\frac{\Delta P}{2 H_{s y s}} t . \\
\text { RoCoF }=\frac{\Delta P}{2 H_{s y s}} .
\end{gathered}
$$

In addition to frequency fluctuation, the huge penetration of PEC technologies creates other stability issues in a power system. The rotor angle stability and the small-signal stability of a power system are directly linked to the synchronous generators connected to the grid [121]. The huge penetration of PEC-based RESs reduces the proportion of synchronous generators in a power system, which may affect the shape, frequency, and damping factor of the rotor oscillation [10]. Furthermore, the power system is unable to use the power system stabilizer connected to the synchronous generator. In the case of large disturbances, transient instability may also occur in the system via changing the power flow in tie-lines [122]. The frequency stability is also linked to the rotor angle stability since the rotor speed of the generators is adjusted on the basis of the system's frequency [123]. Since PEC-based technologies have the ability to control the active and reactive power on both the generation and the load sides, they can be used to maintain rotor angle stability and the frequency stability in the pipeline [116,124]. Furthermore, a low-inertia power system would be capable of maintaining the frequency balance during a significant deviation via rapid generation/load changes [125]. 

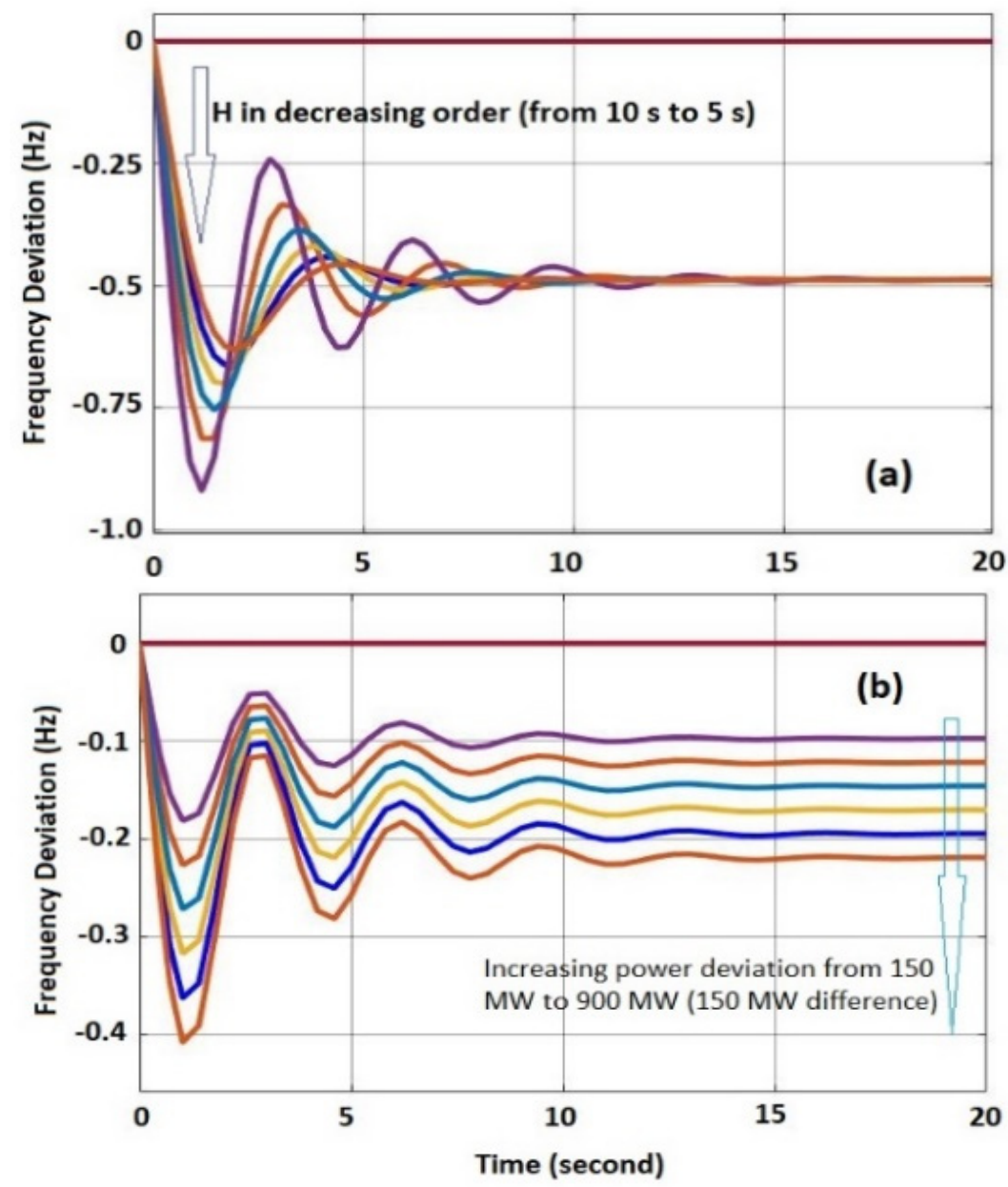

Figure 10. Frequency dynamics for (a) different inertial constants and (b) different power deviations.

On the other hand, PEC-based technologies introduce two new forms of stability issues: resonance and converter-driven stability. The first (i.e., resonance stability) occurs during the periodic exchange of energy in an oscillatory manner because of the insufficient dissipation of energy while magnifying the magnitude of the parameters (i.e., voltage, current, torque, etc.) [10]. Two types of resonance stability exist: (a) torsional and (b) electrical resonance. Torsional resonance basically occurs in conventional power systems that contain synchronous generators, whereas electrical resonance occurs in systems containing RESs (especially variable-speed induction generators in wind turbines). This resonance can lead to large oscillations in current and voltage, as well as large perturbations in electrical torque, which further impact the electrical and mechanical components [10]. Similarly, the second (i.e., converter-driven stability) is fully associated with PEC control and occurs in the form of oscillation due to the cross-coupling phenomenon between the dynamic electromechanical devices and the transient nature of electromagnetic grid networks [11].

\subsection{Future Studies}

According to the literature, the adopted approach of system stability involves the control of appropriate mechanisms by taking into consideration some response parameters. However, with respect to the abovementioned issues, the classical methods cannot effectively address the problems because of their slow response, low accuracy, and poor robustness. Generation-side control approaches are mostly focused on the supply/demand balance, whereas frequency fluctuation issues can be effectively addressed by demand-side control methods [126,127]. Response parameters such as RoCoF, nadir frequency, and OD are important indicators of the system's status, allowing intelligent selection of the appropriate control approach. To regulate the system's characteristics and maintain system 
stability, the real-time response must be measured within microseconds, for which an efficient and intelligent controller is necessary. The response time is the primary concern during the implementation of a control mechanism in the system. Moreover, the power generation characteristics from RESs are unpredictable and fluctuate drastically; thus, the controller must be robust so that it can handle abnormal situations. The system is required to manage and protect the components from failure. Furthermore, most studies were conducted for the integration of big plants such as solar farms and wind farms; however, in current practice, people are installing distributed energy systems on smaller scales $[128,129]$. Various trading practices and control mechanisms are being introduced, which further leads to problems in system operation and protection $[130,131]$. Such problems must be addressed by bottom-up approaches and not only for big power plants. Several studies have been conducted to address the issues of low-inertia power systems, but concrete results were not achieved with practical and efficient validation, and several limitations were identified. Some potential fields of study are discussed in this section to address the current issues of PEC-dominated power systems.

\subsubsection{Grid-Forming Power Converters}

Conventional inverters were designed to work as current sources concerning the grid parameters, whereby synchronous generators are basically used as the reference system (i.e., slack bus), and the generators connected to the inverter act as the power contributors (i.e., following type). These conventional inverters use PLL to synchronize the connected power generators to the power grid [132]. However, the inverter must be able to handle occasional perturbations such as sudden voltage fluctuations and phase changes so as to re-establish the system synchronization [133]. With the increase in the proportion of nonsynchronous generators, modern power systems are becoming dominated by PEC technologies, and the concept of grid-following inverters is becoming outdated due to the need for a reference system (i.e., synchronous generator) to maintain the parameters [107]. Hence, a form of PEC-based resource must be introduced into modern power systems to set the relevant parameters, instead of following the existing values (as done by grid-following inverters).

A grid-forming power converter is a power electronic unit that helps to control the voltage amplitude and frequency (i.e., magnitude and angle of the voltage) at the point of common coupling (PCC) within a power system [134,135]. Its main function is to regulate the output voltage and/or current so that the system frequency and the voltage remain in an acceptable range. Since a grid-forming converter is capable of injecting instantaneous active and reactive power for frequency and voltage regulation within a system, it can be considered as the slack bus unit in an isolated energy system $[134,136]$. However, it can be used in both isolated and grid-connected mode, behaving as a synchronous generator in traditional power systems [134]. Basically, the grid-forming inverter adopts four techniques, as shown in Figure 11. The concept of the grid-forming inverter with new adaptations can address the above-discussed issues, but its actual characteristics, response, and impact are unknown [137]. Numerous studies have proposed adaptions, along with a description of their performance, in the past few years. One of the popular methods used with synchronous generators and inverters is droop control, which established a linear relationship between frequency (active power) and voltage (reactive power) [138] A fractional-order controller for a grid-forming inverter was proposed with the target group of high-energy applications, but the system dynamics were found to be slow and unstable $[139,140]$. Virtual oscillator control-based strategies were proposed in $[141,142]$ for performance improvement, but these approaches are still in the experimental phase and need genuine validation. A sliding mode control was proposed for an AC voltage loop with an inner current loop in [143], but this concept is quite complicated and suffers from high computational cost. Similarly, state-feedback control techniques for direct AC voltage control within a grid-forming inverter have coupling issues with the active power [144] From the studies taken from the literature, it can be observed that the adaptation processes of new concepts with grid-forming inverters are in progress, but no practical and reliable 
solutions have been obtained to date. Some significant research can be done in this sector for the advancement of this concept in the future. For example, the combination of multiple grid-forming concepts (e.g., a hybrid model of a virtual oscillator and matching control) can be conducted by highlighting the strengths and neglecting the drawbacks of specific methods (i.e., the virtual oscillator control method has the best large-signal behavior, while matching control method is more robust; thus, a better result can be achieved through their combination) [145].

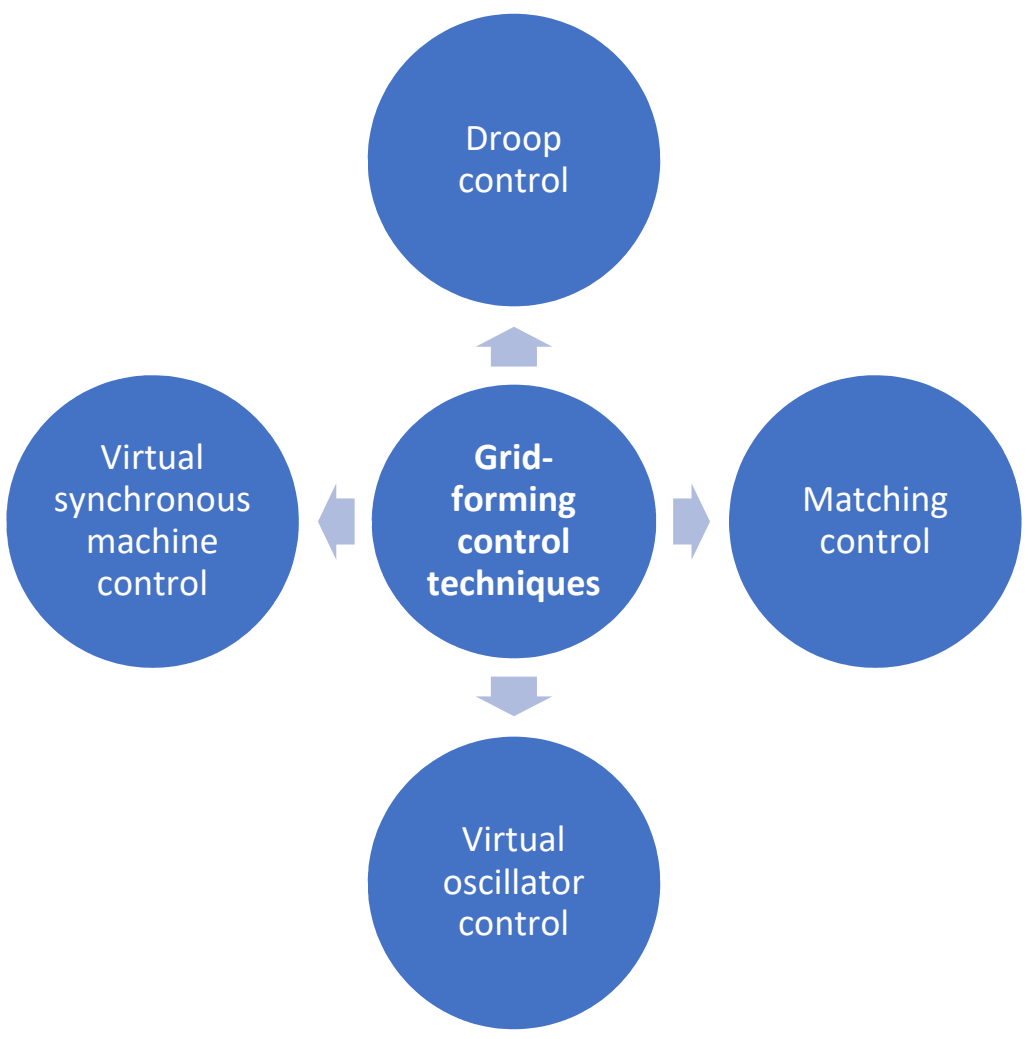

Figure 11. Different techniques used in grid-forming converters.

\subsubsection{VPP/VSG with a New Dimension}

PEC-based generators use a droop control mechanism to maintain frequency, but most of them adopt the approach of power sharing in a steady-state but not transient mode [146]. In addition, the droop control mechanism lacks technical parameters, including system inertia, which was addressed by the introduction of a concept called virtual power plant (VPP) or virtual synchronous generator (VSG) $[147,148]$. The VPP produces the required inertia virtually by introducing an appropriate amount of power, and the inertia minimized the variation in frequency (both primary and secondary) caused by various factors and events [16,149]. The ability to introduce appropriate power (both active and reactive) for the stability of frequency and voltage is an essential characteristic of an effective VPP [150]. However, it takes a few minutes to switch RESs (especially wind energy) from one steady state to another state during normal operation. Hence, a BESS is always introduced along with VPPs to maintain balanced energy conditions and provide virtual inertia during the transient stage $[150,151]$. On the other hand, the complexity may be increased with an increase in the number of VPPs within the system [152,153].

These challenges can be addressed by maintaining efficient coordination among the VPPs that link and share the required inertial proportion [154]. In order to achieve this objective, intelligent architecture can be introduced to monitor, estimate, and control the parameters on a real-time basis. An example of an intelligent architecture is presented in Figure 12. In the proposed system, the distributed VPPs and BESSs provide virtual inertia for their respective RESs, whereby all systems are controlled via the hierarchical control 
architecture. A short-term time-series forecasting model can be developed to forecast the electrical parameters within the power system, which can be utilized to identify optimum coordination among the associated technologies (i.e., size and location of the VPPs, PECs, and grid parameters), such that the system can be securely and reliably operated. A deep learning-based hierarchical control mechanism can be developed to coordinate the distributed and central control system, as well as dynamically oversee the whole power system for normal operation. The proposed model is based on a distributed concept, which can manage the allocation of power, thereby controlling the whole power system. Various platforms can be used to develop this real-time tool, which allows interpreting and visualizing the data received from hardware in a user-friendly way. One of the main concerns during the design and implementation of the proposed system is that the central control must work in proactive way, since the communication process (i.e., data sending and receiving) takes some time, which may delay the whole control process. For this, the optimization and forecasting models must be efficient and accurate so that the system can promptly predict the characteristics and introduce actions at the right time.

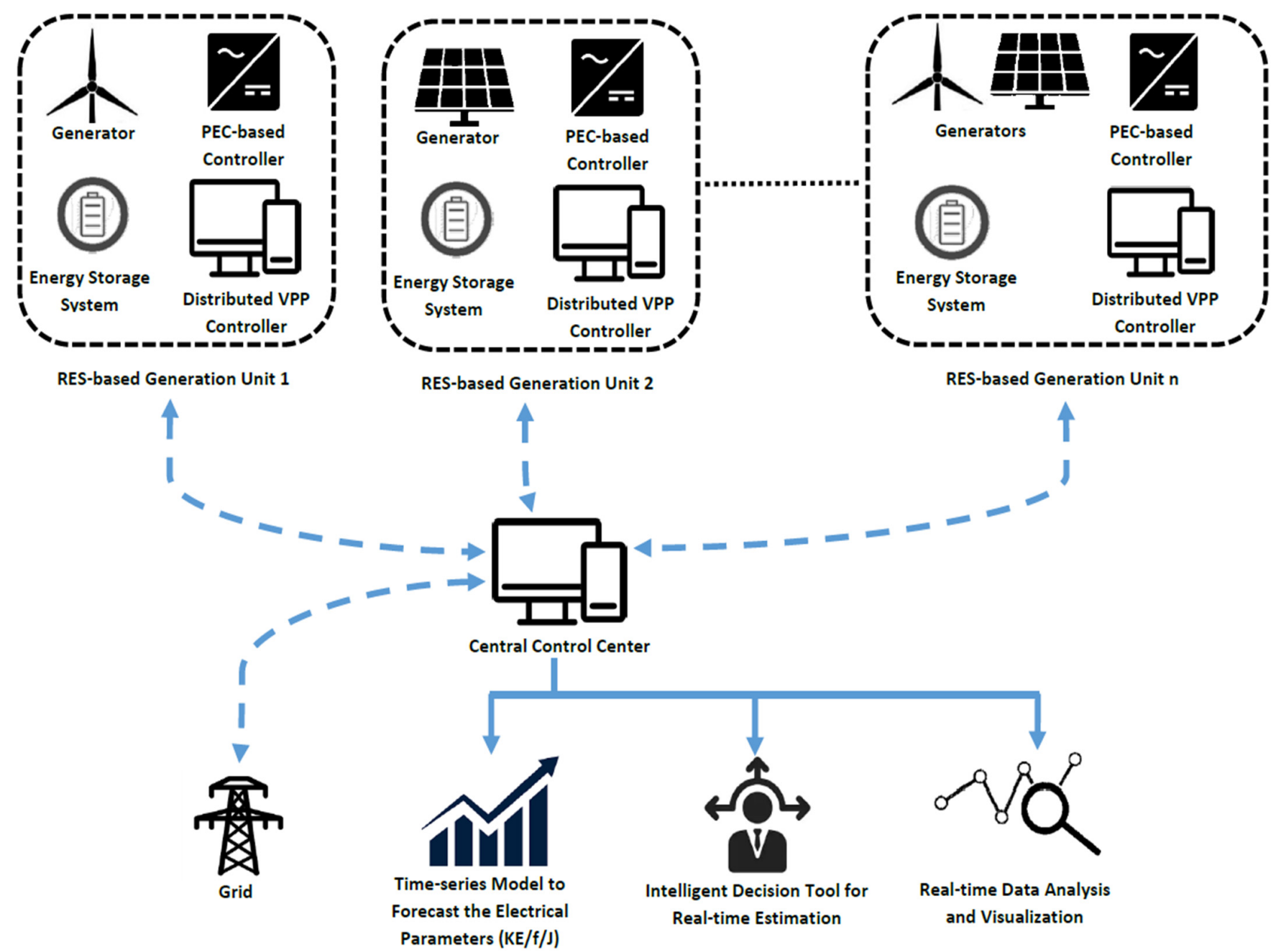

Figure 12. System overview of architecture with intelligent optimization and decision-making model.

\subsubsection{Other Solutions}

With the identified problem of frequency control in low-inertia power systems, numerous potential solutions have been invented and/or are undergoing investigation. Several research articles have proposed efficient and robust methods to address the frequency control issues of low-inertia systems, as listed in Table 3. 
Table 3. List of possible concepts to address the issues occurring in PEC-based power systems.

\begin{tabular}{|c|c|c|}
\hline Concept & Features & References \\
\hline $\begin{array}{l}\text { Inertia emulation via electronic } \\
\text { components and BESSs }\end{array}$ & $\begin{array}{l}\text { This concept introduces electronic devices such as } \\
\text { supercapacitors or BESSs to provide the inertial response to the } \\
\text { power system during a fault or unstable situation (i.e., the } \\
\text { condition of frequency deviation). The reduced power during } \\
\text { power system unbalance or fault can be compensated for by the } \\
\text { introduced components to support the frequency response, } \\
\text { similarly to conventional synchronous generators. Additionally, } \\
\text { this concept helps in system synchronization by providing } \\
\text { virtual control methods. }\end{array}$ & [155] \\
\hline $\begin{array}{l}\text { Incentivizing synchronous condensers or } \\
\text { high-inertia generators }\end{array}$ & $\begin{array}{l}\text { Synchronous condensers can be introduced to provide the } \\
\text { inertia and short-circuit power in low-inertia grid systems via } \\
\text { voltage recovery concepts during system instability. Generally, } \\
\text { this technique considers the emulated generators as } \\
\text { conventional generators, which can provide the required inertia } \\
\text { and the active and reactive powers. One of the complexities of } \\
\text { this technique is the requirement of an optimized technique for } \\
\text { the selection of appropriate capacities and the locations of } \\
\text { emulated generators. }\end{array}$ & {$[156,157]$} \\
\hline $\begin{array}{l}\text { Curtailment methods and grid code } \\
\text { modification }\end{array}$ & $\begin{array}{l}\text { Power production limits, instantaneous combined cycle } \\
\text { generation limits, or price signals can be used to increase the } \\
\text { inertia contribution. This approach is mostly based on the } \\
\text { planning and operation of the existing power system, rather } \\
\text { than adopting new technologies. Furthermore, the existing grid } \\
\text { code can be changed to maintain the system during acceptable } \\
\text { system instability. For example, the operational settings of the } \\
\text { existing control equipment can be revised so as to increase the } \\
\text { acceptable limit, whereby no automatic shutdown would take } \\
\text { place during small levels of deviation. }\end{array}$ & {$[137,158]$} \\
\hline
\end{tabular}

\section{Conclusions}

The introduction of PEC-based technologies is drastically reducing system inertia, thereby leading to numerous issues in power system stability. The inclusion of inertial support might be the best option, but this requires robust, secure, reliable, and practical solutions to maintain the system within an acceptable inertia level. Researches have been conducted to address the problems of low-inertia systems due to PEC-based technologies. However, the proposed studies did not yield concrete results with practical and efficient validation, and several limitations were highlighted. Nevertheless, there are many research gaps in this area which can be filled in the future. On the basis of the studies taken from the literature, two major tasks were identified to address the discussed issues: (a) modification of the grid codes as per the current situation, as well as the adaptation of the new operational strategies; (b) introduction of a new device (maybe PEC-based) for this specific purpose. According to a previous study, the following improvements are recommended: (a) intelligent PEC-based technologies to improve the time response, accuracy, and robustness of controllers and their combinations, (b) intelligent techniques to optimize the rating and coordination of integrated RESs, and (c) intelligent models to optimize the size, number, and location of BESSs within the VPP configuration.

Author Contributions: Conceptualization, A.S.; writing—original draft preparation, A.S.; writingreview and editing, all authors; supervision, F.G.-L. All authors read and agreed to the published version of the manuscript.

Funding: Not applicable.

Institutional Review Board Statement: Not applicable. 
Informed Consent Statement: Not applicable.

Data Availability Statement: The data are available upon request.

Acknowledgments: Ashish Shrestha is thankful to the Department of Electrical Engineering, Information Technology, and Cybernetics, University of South-Eastern Norway, Porsgrunn, Norway, for the support received during his $\mathrm{PhD}$.

Conflicts of Interest: The authors declare no conflict of interest.

\section{References}

1. Verzijlbergh, R.; De Vries, L.; Dijkema, G.; Herder, P. Institutional challenges caused by the integration of renewable energy sources in the European electricity sector. Renew. Sustain. Energy Rev. 2017, 75, 660-667. [CrossRef]

2. Shrestha, A.; Rajbhandari, Y.; Khadka, N.; Bista, A.; Marahatta, A.; Dahal, R.; Mallik, J.K.; Thapa, A.; Hayes, B.P.; Korba, P. Status of Micro/Mini-Grid Systems in a Himalayan Nation: A Comprehensive Review. IEEE Access 2020, 8, 120983-120998. [CrossRef]

3. Shrestha, A.; Rana, L.B.; Singh, A.; Phuyal, S.; Ghimire, A.; Giri, R.; Kattel, R.; Karki, K.; Jha, S.K. Assessment of electricity excess in an isolated hybrid energy system: A case study of a Dangiwada village in rural Nepal. Energy Procedia 2019, 160, 76-83. [CrossRef]

4. Hossain, J.; Mahmud, A. Renewable Energy Integration: Challenges and Solutions; Springer Singapore Heidelberg: Singapore, 2014. [CrossRef]

5. Energy, U. The Challenge of Sustainability. World Energy Assessment, UNDP-WEC. Available online: https: / www.osti.gov / etdeweb/biblio/20228512 (accessed on 2 October 2021).

6. Hou, Q.; Du, E.; Zhang, N.; Kang, C. Impact of High Renewable Penetration on the Power System Operation Mode: A Data-Driven Approach. IEEE Trans. Power Syst. 2019, 35, 731-741. [CrossRef]

7. Bevrani, H. Robust Power System Frequency Control; Springer: Berlin/Heidelberg, Germany, 2009; Volume 85.

8. Hatziargyriou, N.; Milanović, J.; Rahmann, C.; Ajjarapu, V.; Cañizares, C.; Erlich, I.; Hill, D.; Hiskens, I.; Kamwa, I.; Pal, B.; et al. Stability Definitions and Characterization of Dynamic Behavior in Systems with High Penetration of Power Electronic Interfaced Technologies; Technical Report PES-TR77, Power System Dynamic Performance Committee; IEEE Power and Energy Society: Piscataway, NJ, USA, 2020.

9. Peng, Q.; Jiang, Q.; Yang, Y.; Liu, T.; Wang, H.; Blaabjerg, F. On the stability of power electronics-dominated systems: Challenges and potential solutions. IEEE Trans. Ind. Appl. 2019, 55, 7657-7670. [CrossRef]

10. Hatziargyriou, N.; Milanovic, J.; Rahmann, C.; Ajjarapu, V.; Canizares, C.; Erlich, I.; Hill, D.; Hiskens, I.; Kamwa, I.; Pal, B. Definition and Classification of Power System Stability Revisited \& Extended. IEEE Trans. Power Syst. 2020, 36, 3271-3281.

11. Kroposki, B.; Johnson, B.; Zhang, Y.; Gevorgian, V.; Denholm, P.; Hodge, B.-M.; Hannegan, B. Achieving a 100\% renewable grid: Operating electric power systems with extremely high levels of variable renewable energy. IEEE Power Energy Mag. 2017, 15, 61-73. [CrossRef]

12. Wang, Y.; Silva-Saravia, H.; Pulgar-Painemal, H. Actuator placement for enhanced grid dynamic performance: A machine learning approach. IEEE Trans. Power Syst. 2019, 34, 3119-3128. [CrossRef]

13. Pei, W.; Chen, Y.; Sheng, K.; Deng, W.; Du, Y.; Qi, Z.; Kong, L. Temporal-spatial analysis and improvement measures of Chinese power system for wind power curtailment problem. Renew. Sustain. Energy Rev. 2015, 49, 148-168. [CrossRef]

14. Khadka, N.; Paudel, R.; Adhikary, B.; Bista, A.; Sharma, S.; Shrestha, A. Transient Stability in Renewable Energy Penetrated Power Systems: A Review. In Proceedings of the RESSD 2020 International Conference on Role of Energy for Sustainable Social Development in 'New Normal' Era, Kathmandu, Nepal, 28-29 December 2020.

15. Ju, W.; Sun, K.; Yao, R. Simulation of cascading outages using a power-flow model considering frequency. IEEE Access 2018, 6 , 37784-37795. [CrossRef]

16. Othman, M.H.; Mokhlis, H.; Mubin, M.; Talpur, S.; Ab Aziz, N.F.; Dradi, M.; Mohamad, H. Progress in control and coordination of energy storage system-based VSG: A review. IET Renew. Power Gener. 2019, 14, 177-187. [CrossRef]

17. Vandenberghe, F.; Grebe, E.; Klaar, D.; Kleinekorte, K.; Rodriguez, J.; Erven, H.; Tassan, L. FINAL REPORT of the Investigation Committee on the 28 September 2003 Blackout in Italy. UCTE Tech. Rep. 2004. Available online: https://eepublicdownloads. entsoe.eu/clean-documents/pre2015/publications/ce/otherreports/20040427_UCTE_IC_Final_report.pdf (accessed on 8 February 2021).

18. Bevrani, H.; Hiyama, T. Intelligent Automatic Generation Control; CRC Press: New York, NY, USA, 2017.

19. Bevrani, H.; Hiyama, T. On load-frequency regulation with time delays: Design and real-time implementation. IEEE Trans. Energy Convers. 2009, 24, 292-300. [CrossRef]

20. Milla, F.; Duarte-Mermoud, M.A.; Aguila-Camacho, N. Hierarchical mpc secondary control for electric power system. Math. Probl. Eng. 2014, 2014. [CrossRef]

21. Chamorro, H.R.; Sanchez, A.C.; Pantoja, A.; Zelinka, I.; Gonzalez-Longatt, F.; Sood, V.K. A network control system for hydro plants to counteract the non-synchronous generation integration. Int. J. Electr. Power Energy Syst. 2019, 105, 404-419. [CrossRef]

22. Hyndman, R.J.; Liu, X.A.; Pinson, P. Visualizing big energy data: Solutions for this crucial component of data analysis. IEEE Power Energy Mag. 2018, 16, 18-25. [CrossRef] 
23. Bonfiglio, A.; Oliveri, A.; Procopio, R.; Delfino, F.; Denegri, G.; Invernizzi, M.; Storace, M. Improving power grids transient stability via model predictive control. In Proceedings of the 2014 Power Systems Computation Conference, Wroclaw, Poland, 18-22 August 2014; pp. 1-7.

24. Cheng, M.; Sami, S.S.; Wu, J. Benefits of using virtual energy storage system for power system frequency response. Appl. Energy 2017, 194, 376-385. [CrossRef]

25. Lee, S.-J.; Kim, J.-H.; Kim, C.-H.; Kim, S.-K.; Kim, E.-S.; Kim, D.-U.; Mehmood, K.K.; Khan, S.U. Coordinated control algorithm for distributed battery energy storage systems for mitigating voltage and frequency deviations. IEEE Trans. Smart Grid 2015, 7, 1713-1722. [CrossRef]

26. Kumar, P.S. Transient stability enhancement of power system using TCSC. Int. J. Electr. Comput. Eng. 2012, 2, 317. [CrossRef]

27. Wang, M.-H.; Chen, H.-C. Transient stability control of multimachine power systems using flywheel energy injection. IEE Proc. Gener. Transm. Distrib. 2005, 152, 589-596. [CrossRef]

28. Haque, M. Improvement of first swing stability limit by utilizing full benefit of shunt FACTS devices. IEEE Trans. Power Syst. 2004, 19, 1894-1902. [CrossRef]

29. Murali, D.; Rajaram, M.; Reka, N. Comparison of FACTS devices for power system stability enhancement. Int. J. Comput. Appl. 2010, 8, 30-35. [CrossRef]

30. Guo, G.; Wang, Y.; Lim, K.-Y.; Gao, L. Robust nonlinear controller for power system transient stability enhancement with voltage regulation. IEE Proc. Gener. Transm. Distrib. 1996, 143, 407-412. [CrossRef]

31. Teng, F.; Mu, Y.; Jia, H.; Wu, J.; Zeng, P.; Strbac, G. Challenges on primary frequency control and potential solution from EVs in the future GB electricity system. Appl. Energy 2017, 194, 353-362. [CrossRef]

32. Liu, H.; Huang, K.; Wang, N.; Qi, J.; Wu, Q.; Ma, S.; Li, C. Optimal dispatch for participation of electric vehicles in frequency regulation based on area control error and area regulation requirement. Appl. Energy 2019, 240, 46-55. [CrossRef]

33. Aghaei, J.; Alizadeh, M.-I.; Siano, P.; Heidari, A. Contribution of emergency demand response programs in power system reliability. Energy 2016, 103, 688-696. [CrossRef]

34. Babahajiani, P.; Shafiee, Q.; Bevrani, H. Intelligent demand response contribution in frequency control of multi-area power systems. IEEE Trans. Smart Grid 2016, 9, 1282-1291. [CrossRef]

35. Marahatta, A.; Rajbhandari, Y.; Shrestha, A.; Singh, A.; Gachhadar, A.; Thapa, A. Priority-based low voltage DC microgrid system for rural electrification. Energy Rep. 2021, 7, 43-51. [CrossRef]

36. Behera, A.; Panigrahi, T.K.; Sahoo, A.K. A FO-PID Controlled Automatic Generation Control of Multi Area Power Systems Tuned by Harmony Search. Recent Adv. Electr. Electron. Eng. 2020, 13, 101-109. [CrossRef]

37. Tripathy, S.; NAIR, P.C.; Rao, N. Automatic generation control with superconducting magnetic energy storage in power system. Electr. Mach. Power Syst. 1994, 22, 317-338. [CrossRef]

38. Khamari, D.; Sahu, R.K.; Gorripotu, T.S.; Panda, S. Automatic generation control of power system in deregulated environment using hybrid TLBO and pattern search technique. Ain Shams Eng. J. 2019, 11, 553-573. [CrossRef]

39. Xi, L.; Li, Y.; Huang, Y.; Lu, L.; Chen, J. A novel automatic generation control method based on the ecological population cooperative control for the islanded smart grid. Complexity 2018, 2018. [CrossRef]

40. Ramakrishna, K.; Bhatti, T. Automatic generation control of single area power system with multi-source power generation. Proc. Inst. Mech. Eng. Part A J. Power Energy 2008, 222, 1-11. [CrossRef]

41. Zeynelgil, H.; Demiroren, A.; Sengor, N. The application of ANN technique to automatic generation control for multi-area power system. Int. J. Electr. Power Energy Syst. 2002, 24, 345-354. [CrossRef]

42. Nanda, J.; Kaul, B. Automatic generation control of an interconnected power system. Proc. Inst. Electr. Eng. 1978, 125, 385-390. [CrossRef]

43. Sahu, R.K.; Panda, S.; Padhan, S. A hybrid firefly algorithm and pattern search technique for automatic generation control of multi area power systems. Int. J. Electr. Power Energy Syst. 2015, 64, 9-23. [CrossRef]

44. Cui, M.; Khodayar, M.; Chen, C.; Wang, X.; Zhang, Y.; Khodayar, M.E. Deep Learning-Based Time-Varying Parameter Identification for System-Wide Load Modeling. IEEE Trans. Smart Grid 2019, 10, 6102-6114. [CrossRef]

45. Wang, C.; Wang, Z.; Wang, J.; Zhao, D. Robust time-varying parameter identification for composite load modeling. IEEE Trans. Smart Grid 2017, 10, 967-979. [CrossRef]

46. Hung, D.Q.; Mithulananthan, N.; Lee, K.Y. Determining PV penetration for distribution systems with time-varying load models. IEEE Trans. Power Syst. 2014, 29, 3048-3057. [CrossRef]

47. Kiaei, I.; Lotfifard, S. Tube-based model predictive control of energy storage systems for enhancing transient stability of power systems. IEEE Trans. Smart Grid 2017, 9, 6438-6447. [CrossRef]

48. Jin, L.; Kumar, R.; Elia, N. Model predictive control-based real-time power system protection schemes. IEEE Trans. Power Syst. 2009, 25, 988-998. [CrossRef]

49. Ersdal, A.M.; Fabozzi, D.; Imsland, L.; Thornhill, N.F. Model predictive control for power system frequency control taking into account imbalance uncertainty. IFAC Proc. Vol. 2014, 47, 981-986. [CrossRef]

50. Ball, S. Neural Network Predictive Control Applied to Power System Stability. In Intelligent Systems Design and Applications; Springer: Berlin/Heidelberg, Germany, 2003; pp. 43-51.

51. Venkatesh, C.; Deepak, T.; Rajesh, K.; Krishna, K.; Kamath, A. Flatness based TCSC controller for transient stability enhancement of power system. In Proceedings of the 2010 Modern Electric Power Systems, Wroclaw, Poland, 20-22 September 2010; pp. 1-6. 
52. Sun, J.; Zheng, H.; DeMarco, C.L.; Chai, Y. Energy function-based model predictive control with UPFCs for relieving power system dynamic current violation. IEEE Trans. Smart Grid 2016, 7, 2933-2942. [CrossRef]

53. Gómez, J.S.; Sáez, D.; Simpson-Porco, J.W.; Cárdenas, R. Distributed Predictive Control for Frequency and Voltage Regulation in Microgrids. IEEE Trans. Smart Grid 2019, 11, 1319-1329. [CrossRef]

54. Ngamroo, I.; Vachirasricirikul, S. Coordinated control of optimized SFCL and SMES for improvement of power system transient stability. IEEE Trans. Appl. 2011, 22, 5600805. [CrossRef]

55. Fuchs, A.; Imhof, M.; Demiray, T.; Morari, M. Stabilization of large power systems using VSC-HVDC and model predictive control. IEEE Trans. Power Deliv. 2013, 29, 480-488. [CrossRef]

56. Falahi, M.; Lotfifard, S.; Ehsani, M.; Butler-Purry, K. Dynamic model predictive-based energy management of DG integrated distribution systems. IEEE Trans. Power Deliv. 2013, 28, 2217-2227. [CrossRef]

57. Short, J.A.; Infield, D.G.; Freris, L.L. Stabilization of grid frequency through dynamic demand control. IEEE Trans. power Syst. 2007, 22, 1284-1293. [CrossRef]

58. Shi, Q.; Li, F.; Hu, Q.; Wang, Z. Dynamic demand control for system frequency regulation: Concept review, algorithm comparison, and future vision. Electr. Power Syst. Res. 2018, 154, 75-87. [CrossRef]

59. Zhu, Q.; Jiang, L.; Yao, W.; Zhang, C.-K.; Luo, C. Robust load frequency control with dynamic demand response for deregulated power systems considering communication delays. Electr. Power Compon. Syst. 2017, 45, 75-87. [CrossRef]

60. Shi, Q.; Li, F.; Liu, G.; Shi, D.; Yi, Z.; Wang, Z. Thermostatic load control for system frequency regulation considering daily demand profile and progressive recovery. IEEE Trans. Smart Grid 2019, 10, 6259-6270. [CrossRef]

61. Shi, Q.; Cui, H.; Li, F.; Liu, Y.; Ju, W.; Sun, Y. A hybrid dynamic demand control strategy for power system frequency regulation. CSEE J. Power Energy Syst. 2017, 3, 176-185. [CrossRef]

62. Veronica, A.J.; Kumar, N.S.; Gonzalez-Longatt, F. Design of Load Frequency Control for a Microgrid Using D-partition Method. Int. J. Emerg. Electr. Power Syst. 2020, 21. [CrossRef]

63. Tchuisseu, E.T.; Gomila, D.; Brunner, D.; Colet, P. Effects of dynamic-demand-control appliances on the power grid frequency. Phys. Rev. E 2017, 96, 022302. [CrossRef] [PubMed]

64. Mohsenian-Rad, A.-H.; Wong, V.W.; Jatskevich, J.; Schober, R.; Leon-Garcia, A. Autonomous demand-side management based on game-theoretic energy consumption scheduling for the future smart grid. IEEE Trans. Smart Grid 2010, 1, 320-331. [CrossRef]

65. Gonzalez-Longatt, F. Introduction to Power Systems, Presentation Slide. 2019. [CrossRef]

66. Hamon, C.; Perninge, M.; Soder, L. Frequency Control: Operation of Frequency Control Schemes in Power Systems with Large Amounts of Wind Power. Dectoral dissertation, KTH Royal Institute of Technology, Stockholm, Sweden, 2016.

67. ESO. Grid Code (GC), Ofgem, Editor, nationalgridESO. Available online: https://www.nationalgrideso.com/industryinformation/codes / grid-code\#: \{\}:text=The\%20Grid\%20Code\%20details\%20the,of\%20System\%20Code\%20(CUSC) (accessed on 3 December 2021).

68. Group, N.G. The Grid Code Issues 5 Revision 21; National Grid Electricity Transmission: London, UK, 2017.

69. Luo, X.; Wang, J.; Wojcik, J.D.; Wang, J.; Li, D.; Draganescu, M.; Li, Y.; Miao, S. Review of voltage and frequency grid code specifications for electrical energy storage applications. Energies 2018, 11, 1070. [CrossRef]

70. Cobben, S.; Gaiddon, B.; Laukamp, H. Impact of Photovoltaic Generation on Power Quality in Urban Areas with High PV Population: Results from Monitoring Campaigns; Tech. Rep.; Intelligent Energy Europe: Brussels, Belgium, 2008; p. 420208.

71. Hirth, L.; Ziegenhagen, I. Control Power and Variable Renewables: A Glimpse at German Data. 2013. Available online: https:/ / www.feem.it/en/publications/feem-working-papers-note-di-lavoro-series/control-power-and-variable-renewablesa-glimpse-at-german-data/ (accessed on 10 July 2021).

72. Regulator, A.E. (Ed.) Electricity Transmission; Australian Government: Canberra, Australia, 2009.

73. Operator, A.E.M. Black system south Australia 28 September 2016. Rep. Aust. Energy Mark. Oper. Ltd. 2017.

74. Warren, M. South Australia's Blackouts: It's Not Black or White. Available online: https://www.energycouncil.com.au/analysis/ south-australias-blackouts-not-as-simple-as-it-looks / (accessed on 16 September 2020).

75. Christiansen, W.; Johnsen, D.T. Analysis of requirements in selected Grid Codes; Prepared for Orsted-DTU Section of Electric Power Engineering, Technical University of Denmark (DTU): Copenhagen, Denmark, 2006.

76. Cha, S.-T.; Wu, Q.; Østergaard, J. Frequency Stabilizing Scheme for a Danish Island Grid. In Proceedings of the 3rd IEEE PES Innovative Smart Grid Technologies (ISGT) Europe Conference (IEEE PES ISGT Europe 2012), Berlin, Germany, 14-17 October 2012.

77. Møller Andersen, F.; Grenaa Jensen, S.; Larsen, H.V.; Meibom, P.; Ravn, H.; Skytte, K.; Togeby, M. Analyses of Demand Response in Denmark; Risoe National Lab.: Roskilde, Denmark, 2006.

78. DL T 1040-2007 Grid Operation Guidelines; DOC88: Beijing, China, 2007.

79. Handbook, U.O. Appendix 1: Load-Frequency-Control and Performance; UCTE: Brussels, Belgium, 2004.

80. Lazarev, G.; Hrustalyov, V.; Garievskij, M. Non-Baseload Operation in Nuclear Power Plants: Load Following and Frequency Control Modes of Flexible Operation; Nuclear Energy Series; International Atomic Energy Agency: Vienna, Austria, 2018 ; p. 173.

81. Pandurangan, V.; Zareipour, H.; Malik, O. Frequency Regulation Services: A Comparative Study of Select North American and European Reserve Markets. In Proceedings of the 2012 North American Power Symposium (NAPS), Champaign, IL, USA, 9-11 September 2012; pp. 1-8.

82. Gao, D.W.; Muljadi, E.; Tian, T.; Miller, M.; Wang, W. Comparison of Standards and Technical Requirements of Grid-Connected Wind Power Plants in China and the United States; National Renewable Energy Lab. (NREL): Golden, CO, USA, 2016. 
83. 19963-G.T. Technical Rule for Connecting Wind Farm to Power System; State Electricity Regulatory Commission of People's Republic of China: Beijing, China, 2011.

84. Bakshi, A.S.; Croop, D.; Endress, E.; Staschus, K.; Bose, A. Report of Expert Group to Review and Suggest Measures for Bringing Power System Operation Closer to National Reference Frequency; Central Electricity Regulatory Commission: New Delhi, India, 2017.

85. Nath, R.; Bakshi, A.S.; Ravinder, S.; Narasimhan, S.R.; Jain, H.; Shrivastava, S.C. Report of the Expert Group: Review of Indian Electricity Grid Code; Community Emergency Response Team: New Delhi, India, 2020.

86. Community Emergency Response Team. Grid Security Need for Tightening of Frequency Band E Other Measures; Community Emergency Response Team: New Delhi, India, 2011.

87. Committee, E. Report of the Enquiry Committee on Grid Disturbance in Northern Region on 30th July 2012 and in Northern, Eastern $\mathcal{E}$ North-Eastern Region on 31st July, 2012; Central Electricity Regulatory Commission: New Delhi, India.

88. Undrill, J. Notes of Frequency Control for the Australian Energy Market Operator; Australian Energy Market Commission: Canbera, Australia, 2019.

89. Prepared by NERC RS Committee. Balancing and Frequency Control: A Technical Document Prepared by the NERC Resources Subcommittee; NERC Technical Report; NERC RS Committee: Atlanta, GA, USA, 2011.

90. Weckx, S.; D’hulst, R.; Driesen, J. Primary and Secondary Frequency Support by a Multi-Agent Demand Control System. IEEE Trans. Power Syst. 2014, 30, 1394-1404. [CrossRef]

91. Oshnoei, A.; Khezri, R.; Muyeen, S.; Blaabjerg, F. On the contribution of wind farms in automatic generation control: Review and new control approach. Appl. Sci. 2018, 8, 1848. [CrossRef]

92. Tarnowski, G.C. Coordinated Frequency Control of Wind Turbines in Power Systems with High Wind Power Penetration. Ph.D. Thesis, Technical University of Denmark (DTU), Copenhagen, Denmark, 2012.

93. Perninge, M.; Eriksson, R. Optimal tertiary frequency control in power systems with market-based regulation. IFAC-Pap 2017, 50, 4374-4381.

94. Force, S.T. Primary Frequency Response Stakeholder Education Part 1 of 2; PJM: Audubon, PA, USA, 2017; Available online: https://www.pjm.com/-/media/committees-groups/task-forces/pfrstf/20170901/20170901-primary-frequency-responseeducation-part-1-of-2.ashx (accessed on 10 July 2021).

95. Power Returns Following Blackouts. BBC News Channel, 28 May 2008.

96. Milner, M.; Wearden, G. Q \& A: Blackout Britain. The Guardian, 2008.

97. Venezuela Crisis: Fresh Power Cuts Black Out Caracas. BBC News, 26 March 2019.

98. No End in Sight to Venezuela's Blackout, Experts Warn. The New York Times, 11 March 2019.

99. Dayton, R. Maduro's Revolutionary Guards: The Rise of Paramilitarism in Venezuela. SunSentinel, 2019.

100. Blackout Traker: United States Annual Report 2018; EATON Powering Business Worldwide: Ohio, OH, USA, 2019.

101. Nyberg, M. 2019 Total System Electric Generation; California Energy Commission: Sacramento, CA, USA, 2020.

102. Mossburg, C. More than 3 Million California Homes May Lose Power in Record Heat Wave Due to Rolling Blackouts. CNN, USA. 17 August 2020.

103. Borunda, A. Why Renewables aren't to Blame for California's Blackouts. National Geographic, 2020.

104. Kasler, D.; Heerer, M. California Avoided Rolling Blackouts for Two Decades. What Went Wrong on the Grid? The Sacramento Bee, 2020.

105. Haes Alhelou, H.; Hamedani-Golshan, M.E.; Njenda, T.C.; Siano, P. A survey on power system blackout and cascading events: Research motivations and challenges. Energies 2019, 12, 682. [CrossRef]

106. Blackout Tracker: United States Annual Report 2017; EATON Power Business Worldwide: Scottsdale, AZ, USA, 2018.

107. Hodge, B.M.S.; Jain, H.; Brancucci, C.; Seo, G.S.; Korpås, M.; Kiviluoma, J.; Holttinen, H.; Smith, J.C.; Orths, A.; Estanqueiro, A. Addressing technical challenges in $100 \%$ variable inverter-based renewable energy power systems. Wiley Interdiscip. Rev. Energy Environ. 2020, 9, e376. [CrossRef]

108. Alani, A.Y.; Osunmakinde, I.O. Short-term multiple forecasting of electric energy loads for sustainable demand planning in smart grids for smart homes. Sustainability 2017, 9, 1972. [CrossRef]

109. Remon, D.; Cantarellas, A.M.; Mauricio, J.M.; Rodriguez, P. Power system stability analysis under increasing penetration of photovoltaic power plants with synchronous power controllers. IET Renew. Power Gener. 2017, 11, 733-741. [CrossRef]

110. Peters, D.; Kilper, T.; Calais, M.; Jamal, T.; von Maydell, K. Solar short-term forecasts for predictive control of battery storage capacities in remote PV diesel networks. In Transition Towards 100\% Renewable Energy; Springer: Berlin/Heidelberg, Germany, 2018; pp. 325-333.

111. Xu, Y.; Zhang, R.; Zhao, J.; Dong, Z.Y.; Wang, D.; Yang, H.; Wong, K.P. Assessing short-term voltage stability of electric power systems by a hierarchical intelligent system. IEEE Trans. neural Netw. Learn. Syst. 2015, 27, 1686-1696. [CrossRef]

112. Wang, J.; Li, P.; Ran, R.; Che, Y.; Zhou, Y. A short-term photovoltaic power prediction model based on the gradient boost decision tree. Appl. Sci. 2018, 8, 689. [CrossRef]

113. Du, P.; Wang, J.; Yang, W.; Niu, T. A novel hybrid model for short-term wind power forecasting. Appl. Soft Comput. 2019, 80, 93-106. [CrossRef]

114. Barbounis, T.G.; Theocharis, J.B.; Alexiadis, M.C.; Dokopoulos, P.S. Long-term wind speed and power forecasting using local recurrent neural network models. IEEE Trans. Energy Convers. 2006, 21, 273-284. [CrossRef]

115. Negnevitsky, M.; Nguyen, D.H.; Piekutowski, M. Risk assessment for power system operation planning with high wind power penetration. IEEE Trans. Power Syst. 2014, 30, 1359-1368. [CrossRef] 
116. Mitra, A.; Chatterjee, D. Active power control of DFIG-based wind farm for improvement of transient stability of power systems. IEEE Trans. Power Syst. 2015, 31, 82-93. [CrossRef]

117. Tielens, P.; Henneaux, P.; Cole, S. Penetration of renewables and reduction of synchronous inertia in the European power system-Analysis and solutions. ASSET project, DG Energy Unit C.2. European Uunion, 2018.

118. Shrestha, A.; Ghimire, B.; Gonzalez-Longatt, F. A Bayesian Model to Forecast the Time Series Kinetic Energy Data for a Power System. Energies 2021, 14, 3299. [CrossRef]

119. Ulbig, A.; Borsche, T.S.; Andersson, G. Impact of low rotational inertia on power system stability and operation. IFAC Proc. Vol. 2014, 47, 7290-7297. [CrossRef]

120. Zografos, D. Power System Inertia Estimation and Frequency Response Assessment; KTH Royal Institute of Technology: Stockholm, Sweden, 2019.

121. Kundur, P.; Paserba, J.; Ajjarapu, V.; Andersson, G.; Bose, A.; Canizares, C.; Hatziargyriou, N.; Hill, D.; Stankovic, A.; Taylor, C. Definition and classification of power system stability IEEE/CIGRE joint task force on stability terms and definitions. IEEE Trans. Power Syst. 2004, 19, 1387-1401.

122. Kundur, P.; Balu, N.J.; Lauby, M.G. Power System Stability and Control; McGraw-hill: New York, NY, USA, $1994 ;$ Volume 7.

123. Meegahapola, L.; Sguarezi, A.; Bryant, J.S.; Gu, M.; Conde D, E.R.; Cunha, R. Power System Stability with Power-Electronic Converter Interfaced Renewable Power Generation: Present Issues and Future Trends. Energies 2020, 13, 3441. [CrossRef]

124. Munkhchuluun, E.; Meegahapola, L.; Vahidnia, A. The Large Disturbance Rotor Angle Stability with DFIG Wind Farms. In Proceedings of the 2019 9th International Conference on Power and Energy Systems (ICPES), Perth, Australia, 10-12 December 2019; pp. 1-6.

125. Mansouri, N.; Lashab, A.; Sera, D.; Guerrero, J.M.; Cherif, A. Large photovoltaic power plants integration: A review of challenges and solutions. Energies 2019, 12, 3798. [CrossRef]

126. Qdr, Q. Benefits of Demand Response in Electricity Markets and Recommendations for Achieving Them; Tech. Rep; US Dept. Energy: Washington, DC, USA, 2006.

127. Albadi, M.H.; El-Saadany, E.F. A summary of demand response in electricity markets. Electr. Power Syst. Res. 2008, 78, 1989-1996. [CrossRef]

128. Khadka, N.; Bista, A.; Adhikari, B.; Shrestha, A.; Bista, D.; Adhikary, B. Current Practices of Solar Photovoltaic Panel Cleaning System and Future Prospects of Machine Learning Implementation. IEEE Access 2020, 8, 135948-135962. [CrossRef]

129. Shrestha, A.; Bishwokarma, R.; Chapagain, A.; Banjara, S.; Aryal, S.; Mali, B.; Thapa, R.; Bista, D.; Hayes, B.P.; Papadakis, A. Peer-to-peer energy trading in micro/mini-grids for local energy communities: A review and case study of Nepal. IEEE Access 2019, 7, 131911-131928. [CrossRef]

130. Shrestha, A.; Kattel, R.; Dachhepatic, M.; Mali, B.; Thapa, R.; Singh, A.; Bista, D.; Adhikary, B.; Papadakis, A.; Maskey, R.K. Comparative study of different approaches for islanding detection of distributed generation systems. Appl. Syst. Innov. 2019, 2, 25. [CrossRef]

131. Shrestha, P.; Shrestha, A.; Shrestha, N.T.; Papadakis, A.; Maskey, R.K. Assessment on scaling-up of mini-grid initiative: Case study of mini-grid in rural Nepal. Int. J. Precis. Eng. Manuf.-Green Technol. 2021, 8, 217-231. [CrossRef]

132. Dong, D.; Wen, B.; Boroyevich, D.; Mattavelli, P.; Xue, Y. Analysis of phase-locked loop low-frequency stability in three-phase grid-connected power converters considering impedance interactions. IEEE Trans. Ind. Electron. 2014, 62, 310-321. [CrossRef]

133. Anani, N.; Al-Kharji AlAli, O.; Al-Qutayri, M.; Al-Araji, S. Synchronization of a renewable energy inverter with the grid. J. Renew. Sustain. Energy 2012, 4, 043103. [CrossRef]

134. Rocabert, J.; Luna, A.; Blaabjerg, F.; Rodriguez, P. Control of power converters in AC microgrids. IEEE Trans. Power Electron. 2012, 27, 4734-4749. [CrossRef]

135. Paquette, A.D.; Reno, M.J.; Harley, R.G.; Divan, D.M. Sharing transient loads: Causes of unequal transient load sharing in islanded microgrid operation. IEEE Ind. Appl. Mag. 2013, 20, 23-34. [CrossRef]

136. Paolone, M.; Gaunt, T.; Guillaud, X.; Liserre, M.; Meliopoulos, S.; Monti, A.; Van Cutsem, T.; Vittal, V.; Vournas, C. Fundamentals of power systems modelling in the presence of converter-interfaced generation. Electr. Power Syst. Res. 2020, 189, 106811. [CrossRef]

137. Johnson, S.C.; Rhodes, J.D.; Webber, M.E. Understanding the impact of non-synchronous wind and solar generation on grid stability and identifying mitigation pathways. Appl. Energy 2020, 262, 114492. [CrossRef]

138. De Brabandere, K.; Bolsens, B.; Van den Keybus, J.; Woyte, A.; Driesen, J.; Belmans, R. A voltage and frequency droop control method for parallel inverters. IEEE Trans. Power Electron. 2007, 22, 1107-1115. [CrossRef]

139. Qoria, T.; Gruson, F.; Colas, F.; Guillaud, X.; Debry, M.-S.; Prevost, T. Tuning of cascaded controllers for robust grid-forming Voltage Source Converter. In Proceedings of the 2018 Power Systems Computation Conference (PSCC), Dublin, Ireland, 11-15 June 2018; pp. 1-7.

140. D'Arco, S.; Suul, J.A.; Fosso, O.B. Automatic tuning of cascaded controllers for power converters using eigenvalue parametric sensitivities. IEEE Trans. Ind. Appl. 2014, 51, 1743-1753. [CrossRef]

141. Johnson, B.B.; Sinha, M.; Ainsworth, N.G.; Dörfler, F.; Dhople, S.V. Synthesizing virtual oscillators to control islanded inverters. IEEE Trans. Power Electron. 2015, 31, 6002-6015. [CrossRef]

142. Seo, G.-S.; Colombino, M.; Subotic, I.; Johnson, B.; Groß, D.; Dörfler, F. Dispatchable virtual oscillator control for decentralized inverter-dominated power systems: Analysis and experiments. In Proceedings of the 2019 IEEE Applied Power Electronics Conference and Exposition (APEC), Anaheim, CA, USA, 17-21 March 2019; pp. 561-566. 
143. Li, Z.; Zang, C.; Zeng, P.; Yu, H.; Li, S.; Bian, J. Control of a Grid-Forming Inverter Based on Sliding-Mode and Mixed $\mathrm{H}_{2} / \mathrm{H}_{\infty}$ Control. IEEE Trans. Ind. Electron. 2016, 64, 3862-3872. [CrossRef]

144. Qoria, T.; Li, C.; Oue, K.; Gruson, F.; Colas, F.; Guillaud, X. Direct AC voltage control for grid-forming inverters. J. Power Electron. 2020, 20, 198-211. [CrossRef]

145. Dörfler, F. Control of Power Converters in Low-Inertia Power Systems. In KTH Workshop: Emerging Topics in Control of Power Systems; KTH Campus: Södertälje, Sweden; Available online: https:/ / sites.google.com/view/kth-topics-power-system/home (accessed on 12 December 2020).

146. Liang, X.; Karim, C.A.B. Virtual synchronous machine method in renewable energy integration. In Proceedings of the 2016 IEEE PES Asia-Pacific Power and Energy Engineering Conference (APPEEC), Xi'an, China, 25-28 October 2016; pp. 364-368.

147. Yap, K.Y.; Sarimuthu, C.R.; Lim, J.M.-Y. Virtual Inertia-Based Inverters for Mitigating Frequency Instability in Grid-Connected Renewable Energy System: A Review. Appl. Sci. 2019, 9, 5300. [CrossRef]

148. Mosca, C.; Arrigo, F.; Mazza, A.; Bompard, E.; Carpaneto, E.; Chicco, G.; Cuccia, P. Mitigation of frequency stability issues in low inertia power systems using synchronous compensators and battery energy storage systems. IET Gener. Transm. Distrib. 2019, 13, 3951-3959. [CrossRef]

149. Liu, J.; Hossain, M.; Lu, J.; Rafi, F.; Li, H. A hybrid AC/DC microgrid control system based on a virtual synchronous generator for smooth transient performances. Electr. Power Syst. Res. 2018, 162, 169-182. [CrossRef]

150. Bevrani, H.; Ise, T.; Miura, Y. Virtual synchronous generators: A survey and new perspectives. Int. J. Electr. Power Energy Syst. 2014, 54, 244-254. [CrossRef]

151. Shintai, T.; Miura, Y.; Ise, T. Oscillation damping of a distributed generator using a virtual synchronous generator. IEEE Trans. Power Deliv. 2014, 29, 668-676. [CrossRef]

152. Liu, J.; Miura, Y.; Ise, T. Power quality improvement of microgrids by virtual synchronous generator control. In Proceedings of the 2016 Electric Power Quality and Supply Reliability (PQ), Tallinn, Estonia, 29-31 August 2016; pp. 119-124.

153. D'Arco, S.; Suul, J.A. A synchronization controller for grid reconnection of islanded virtual synchronous machines. In Proceedings of the 2015 IEEE 6th International Symposium on Power Electronics for Distributed Generation Systems (PEDG), Aachen, Germany, 22-25 June 2015; pp. 1-8.

154. Poolla, B.K.; Bolognani, S.; Dörfler, F. Optimal placement of virtual inertia in power grids. IEEE Trans. Autom. Control. 2017, 62, 6209-6220. [CrossRef]

155. Peña Asensio, A.; Gonzalez-Longatt, F.; Arnaltes, S.; Rodríguez-Amenedo, J.L. Analysis of the Converter Synchronizing Method for the Contribution of Battery Energy Storage Systems to Inertia Emulation. Energies 2020, 13, 1478. [CrossRef]

156. Marrazi, E.; Yang, G.; Weinreich-Jensen, P. Allocation of synchronous condensers for restoration of system short-circuit power. J. Mod. Power Syst. Clean Energy 2018, 6, 17-26. [CrossRef]

157. ElectraNet. Economic Life for ElectraNEt Synchronous Condensers; GHD Advisory: Canbera, Australia, 2019.

158. Energy Sector Management Assistance Program. Grid Integration Requirements for Variable Renewable Energy; World Bank eLibrary: Washington, DC, USA, 2019. 